Article

\title{
Where Diffusion of Clean Technologies and Barriers to Innovation Clash: Application to the Global Diffusion of the Electrical Arc Furnace
}

\author{
José Antonio Moya \\ Joint Research Centre, P.O. Box 2, 1755 ZG Petten, The Netherlands; jose.moya@ec.europa.eu; \\ Tel.: +31-224-56-5224 \\ Academic Editor: Patrik Thollander \\ Received: 27 October 2016; Accepted: 12 January 2017; Published: 17 January 2017
}

\begin{abstract}
This paper analyses the role of barriers preventing the worldwide take-up of a clean technology: the electrical arc furnace. It also identifies which barriers affect a parameter that summarises the combined effect of all of them. The first step, determination of the combined effect of the barriers, is carried out using a novel approach to model the diffusion of innovations. This new approach is composed only by terms that account for the driver of innovations and the parameter that summarises the effect of barriers. The objective quantification of the effect of barriers in the diffusion of innovations opens up new opportunities for designing policies to overcome the barriers identified as the most relevant, for identifying the effect of existing policies, for relating innovation indicators with those barriers or for better incorporating the effect of barriers in bottom-up models that forecast the technological evolution of the economy.
\end{abstract}

Keywords: diffusion of innovations; energy-system models; energy efficiency gap; barriers; industrial energy efficiency

\section{Introduction}

This paper links two broad fields that, although deeply related, are not usually treated simultaneously in the scientific literature: the modeling of diffusion of innovations and the description of barriers faced by cost-effective investments. The effect of barriers preventing investments is so pervasive that the literature of energy efficiency [1-3] has introduced the term "energy-efficiency-gap". This term refers to the discrepancy between the observed level of diffusion of a technology and the economically optimal level. However, when accounting for the spread of innovation, none of the models on diffusion of technologies (see some comprehensive reviews in [4-6]), specifically include the overall effect of barriers in their mathematical formulation. Note that already in 1994, Jaffe [7] developed a framework to describe the very gradual diffusion of apparently cost-effective energy-conservation technologies in the building sector. Their analysis, based on the incorporation of the effect of some specific barriers affecting the attractiveness of the investments, confirms the existence of the "energy paradox". Recently, Moya [8] developed a new general approach to describe the diffusion of innovations in terms of its main drivers and barriers. Unlike Jaffe [7], this latter general approach enables us to quantify in just one term the overall effect of the barriers to the spread of electrical arc furnace technology (EAF). The second section of this paper shows the suitability of this approach to account for the global diffusion of EAF in the last forty years. Note that so far, in the scientific literature on barriers (Sorrell et al. [9] provide a large number of references), the main source of empirical information about barriers comes from surveys or interviews with decision makers. Based on this information, several taxonomies of barriers have been defined and subsequently improved [9-13]. This information has also been used to conduct profit models [14] and analyse the relevance of barriers. However, according to the original approach of Moya [8], the overall effect of barriers 
in the diffusion of innovations can be estimated from historical records about how the diffusion has taken place. This represents a very novel source of information with huge potential to analyse the relevance of barriers. Unlike the answers to surveys, this source of information collects a factual answer over time from decision makers about the actual relevance of barriers. The third section of this paper analyses which barriers have the highest influence over the summarising parameter of the effect of barriers.

It is easy to understand the interest of policy-makers in unravelling the mechanisms of diffusion of innovations [15-17] and how barriers are preventing sound investments. This understanding can support the design of policies to reduce the impact of barriers [16,18-20]. Moreover, regarding energy demand forecasts, there are two typically separated groups of models, top-down and bottom-up models. Whereas the former is the first choice of economists, the main trait of the latter is the further detailed description of technologies. Therefore, they have the potential to model the effects of technology-oriented policies. Algehed et al. [21] compare top-down and bottom-up models, Worrell et al. [22] is more focused on the development needs of these latter models and Fleiter et al. [20] is focused on the role of barriers in bottom-up models. This last reference concludes with the need to represent the effect of the barriers in these models in a less aggregated and not so simplified manner. Although the approach proposed in Moya [8] also summarises the effect of barriers in a single parameter, this simplification comes from a theoretical background. Therefore, it makes sense to analyse the sensitivity of this single parameter to potential barriers (as done in Section 3 of this paper). The replication of the findings for other technologies will allow for a review of how the decision-making criterion of investment in new technologies is incorporated into bottom-up models. Furthermore, the inclusion of the effect and intensity of barriers into these models will also allow an analysis of policies aimed to remove those barriers.

\section{Diffusion of EAF Based on the Drivers of Innovation Diffusion and the Overall Effect of Barriers}

This paper follows the approach to modelling the diffusion of innovations presented in [8]. In this approach, the diffusion of innovations happens in a social medium formed by stakeholders (innovators, potential adopters, regulators ... ). In this social medium, there are potential barriers that affect the driver of the innovations. Mathematically, the diffusion of innovations can be expressed by the diffusion equation of natural processes:

$$
\boldsymbol{K} \delta^{2} h / \delta x^{2}=\delta h / \delta t,
$$

The application of this expression to the diffusion of innovations requires the conceptual abstraction of assimilating the spatial dimension $x$ to the dimension of the social medium (geographical context, interaction among stakeholders, regulators, technology providers ... ) in which the diffusion takes place. $h$ is the driver or the innovations (cost-effective investments). Since the innovation process is based on individual decisions made by innovators, Moya [8] uses as a driver of innovations a function that collects the main parameters that historically have influenced cost-effectiveness analysis of any investment in the innovation. $K$ is the permeability or innovation conductivity in the social medium. For some conditions (1) can be solved analytically, provided the coefficient $K$ is constant [23]; In order to get the analytical solution (2) we can apply the Laplace transformation to (1) to convert the partial differential Equation (1) into an ordinary differential equation. When $x=L$ and the input in the system (the driver of innovations) is a Dirac's delta the anti-transformed of the solution of ordinary differential equation is:

$$
R(x=L, t)=\frac{L e^{-\frac{L^{2}}{4 K t}}}{2 \sqrt{\pi K t^{3}}}
$$

This function is known as a response function. The solution to any arbitrary $f(t)$, that is, when the boundaries conditions are $h=f(t)$ for $x=0$ and $t>0$ and $h=0$ for $t=0$ at any $x>0$ can be obtained by taking advantage of the linearity of the problem to apply the superposition principle. The application 
of this principle boils down to the application of the convolution integral (3) between the response function and the input $f(t)$ :

$$
h(x=L, t)=\int_{0}^{t} f(t-\tau) \frac{L}{2 \tau \sqrt{\pi K \tau}} \exp \left(-\frac{L^{2}}{4 K \tau}\right) d \tau
$$

In practical terms, to solve (1), first, we need to fix the value of the societal dimension (let us say $x=L)$ in which the problem is solved. Moreover, pairs of $L$ and $K$ that keep the same value of $L^{2} / K$ produce the same solution in (3). Moya [8] uses a linear combination of the steel, scrap and electricity price as $f(t)$. This function $f(t)$, is able to explain the number of cost-effective innovations (main driver of the diffusion process), and has the form:

$$
f(t)=\beta_{0}+\beta_{1} \text { SteelPrice }(t)+\beta_{2} \operatorname{ScrapPrice}(t)+\beta_{3} \operatorname{ElectricityPrice}(t),
$$

For each country included in the analysis, the regressors $\beta_{0}, \beta_{1}, \beta_{2}, \beta_{3}$, and the coefficient $K$ can be estimated minimising the difference between the solution of (3) and the observed diffusion in those countries.

The selection of terms included in Equation (4) disregards other factors that could influence a cost-effectiveness analysis. Some examples of these factors could be the improvement of the energy efficiency of the EAF technology with time, the breakdown of the electricity price in its different components (energy price and transmission tariffs), the presence of power plants in existing steel mills (that could facilitate cheaper electricity prices for the uptake of this technology by the incumbents), etc. However, as the next section shows, the simple combination of parameters considered in Equation (4) is enough per se to reproduce quite closely the historical diffusion of the EAF in most of the countries analysed.

\subsection{Application of This New Approach to Model the Diffusion of Innovations to the Worldwide Difusion of EAF}

Herein we apply this novel approach to model the historical penetration of the EAF technology in the global steel industry. In 200136 countries accounted for around $83 \%$ of the EAF installed capacity.

The diffusion of technology innovations in the steel industry has been studied quite intensively [24]. There are also some diffusion studies on the electric arc furnace [25-27]. Moya [8] proves that scrap prices, energy prices and steel price are enough to explain the empirical diffusion pattern of this technology in Japan using a simple ARMAX model. Thanks to their leverage, these parameters are used in Moya [8] as the driver of innovations in expression (4) when applying the methodology previously described. The values used, given in Table 1, come from [28-30].

Table 1. Constant prices (in 2005 Euros) of steel, scrap and electricity used in $f(t)$ of Equations (3) and (4).

\begin{tabular}{cccc}
\hline & Steel & Scrap & Electricity \\
\cline { 2 - 4 } & EUR/t & EUR/t & EUR/MWh \\
\hline 1974 & 850 & 273 & 103 \\
1975 & 778 & 167 & 98 \\
1976 & 738 & 172 & 95 \\
1977 & 695 & 132 & 92 \\
1978 & 649 & 149 & 89 \\
1979 & 600 & 176 & 89 \\
1980 & 551 & 151 & 89 \\
1981 & 477 & 140 & 90 \\
1982 & 348 & 89 & 92 \\
1983 & 307 & 99 & 94 \\
1984 & 311 & 115 & 97 \\
1985 & 291 & 89 & 100 \\
1986 & 278 & 92 & 98 \\
\hline
\end{tabular}


Table 1. Cont.

\begin{tabular}{cccc}
\hline & Steel & Scrap & Electricity \\
\cline { 2 - 4 } & EUR/t & EUR/t & EUR/MWh \\
\hline 1987 & 250 & 104 & 98 \\
1988 & 313 & 128 & 98 \\
1989 & 392 & 122 & 97 \\
1990 & 403 & 117 & 95 \\
1991 & 393 & 98 & 90 \\
1992 & 321 & 89 & 84 \\
1993 & 357 & 115 & 79 \\
1994 & 323 & 127 & 75 \\
1995 & 374 & 132 & 72 \\
1996 & 347 & 126 & 70 \\
1997 & 308 & 124 & 67 \\
1998 & 241 & 101 & 63 \\
1999 & 216 & 87 & 56 \\
2000 & 220 & 87 & 46 \\
2001 & 195 & 66 & 51 \\
2002 & 177 & 77 & 55 \\
2003 & 227 & 101 & 59 \\
2004 & 356 & 170 & 62 \\
2005 & 340 & 152 & 68 \\
2006 & 346 & 167 & 75 \\
2007 & 396 & 189 & 78 \\
2008 & 566 & 260 & 86 \\
2009 & 359 & 154 & 97 \\
2010 & 411 & 233 & 98 \\
2011 & 451 & 281 & 106 \\
\hline
\end{tabular}

Since it was not possible to find the evolution of the electricity price in some of the analysed countries, the German electricity price is used as a proxy for all of them. There is a high correlation $(0.90)$ between the values of the coefficient $K$ obtained using the electricity prices for countries for which this data is available and the ones obtained (third column of Table 2) when using the German electricity prices as a proxy. Nevertheless, we opt for this second option for all countries in order avoid introducing a systematic bias in the estimations of some of the $K$ values. All values in Table 1 are in constant 2005 prices in Euros (that is, removing the effect of inflation), from [31].The solution $E A F_{\text {estimated }}$ of the diffusion process (at $x=L$ ) is the result of the integral of convolution given in (3) using as $f(t)$ the Function (4). In principle, to estimate $E A F_{\text {estimated }}$ first we have to adjust 6 parameters, $\beta_{0}, \beta_{1}, \beta_{2}, \beta_{3}, L$ and $K$. However, since the solution is invariant for the same values of $L^{2} / K$, we fix the value of the $L$ and vary the $K$. All in all, the model requires the adjustment of 5 parameters that can be found by minimising the sum of squared errors between the value $E A F_{\text {estimated }}$ estimated by the model and the values observed $E A F_{\text {observed }}$; in other words, finding the minimum:

$$
\min \left\{\sum_{t=1970}^{t=2010}\left[E A F_{\text {observed }}(t)-E A F_{\text {estimated }}(t)\right]^{2}\right\}
$$

The blue curves of Figure A1 of Appendix A give the historical evolution of the penetration share of the EAF technology ( $\left.E A F_{\text {observed }}\right)$ in each of the 36 countries analysed. These values come from [32]. The green curves of Figure A1, the $E A F_{\text {estimated }}$, are the best fit of obtained for $E A F_{\text {observed }}$. The values of coefficients $\beta_{0}, \beta_{1}, \beta_{2}, \beta_{3}$ and $K$ that minimise (5) are given in Table 2. These coefficients can be obtained by using the code published in Appendix A of Moya [8] to solve the minimisation (5).

The two right-hand columns of Table 2 provide two different measures of the estimation error: the root-mean-square error (RMSE) and the mean absolute error MAE. Note in some countries, such as Denmark, Portugal or Iran, although the model is able to reproduce the observed behaviour, the 
changes in the penetration of the EAF happened so quickly that all the error is produced around the change zone, being most of the mean absolute error, that in these three cases goes up to around $10 \%$.

Table 2. Values of $K$ and the parameters $\beta_{0}, \beta_{1}, \beta_{2}, \beta_{3}$ that produce the best fit between the percentage of EAF observed and estimated.

\begin{tabular}{|c|c|c|c|c|c|c|c|c|c|}
\hline & & $K$ & $\begin{array}{c}\beta_{0} \\
\text { (cte.) }\end{array}$ & $\begin{array}{c}\beta_{1} \\
\text { (steel) }\end{array}$ & $\frac{\beta_{2}}{\text { (scrap) }}$ & $\begin{array}{c}\beta_{3} \\
\text { (elec.) }\end{array}$ & $R^{2}$ & RMSE & MAE \\
\hline Belgium & $\mathrm{BE}$ & 0.0046 & -105.4760 & -0.3101 & 4.4448 & 0.2571 & 0.97 & 1.99 & 1.48 \\
\hline Germany & $\mathrm{DE}$ & 0.0236 & 90.7210 & 0.0473 & -0.0958 & -0.6866 & 0.94 & 1.54 & 1.36 \\
\hline Spain & ES & 0.0469 & 165.2440 & 0.0904 & -0.2790 & -1.2160 & 0.97 & 2.19 & 1.84 \\
\hline France & FR & 0.0166 & -59.6321 & -0.0703 & -0.1259 & 2.1585 & 0.98 & 1.59 & 1.33 \\
\hline Italy & IT & 0.0700 & 33.5673 & -0.0257 & 0.1921 & -0.2313 & 0.93 & 1.73 & 1.37 \\
\hline Poland & PL & 0.0043 & 1.2579 & 0.2498 & 1.8643 & 1.5431 & 0.96 & 2.42 & 2.02 \\
\hline Portugal & PT & 0.0067 & -6.3665 & -1.7675 & 6.8168 & 5.8099 & 0.80 & 12.27 & 9.75 \\
\hline Finland & FI & 0.0066 & 11.5788 & -0.1851 & -3.5585 & 6.8785 & 0.81 & 2.76 & 2.17 \\
\hline Sweden & SE & 0.0290 & -4.2775 & 0.3045 & -0.2654 & -1.1562 & 0.89 & 2.25 & 1.79 \\
\hline U. Kingdom & UK & 0.0848 & -29.0947 & 0.0848 & 0.0000 & -0.0867 & 0.86 & 1.78 & 1.42 \\
\hline Japan & $\mathrm{JP}$ & 0.0385 & -28.5446 & 0.1021 & -0.4049 & 0.7416 & 0.97 & 0.74 & 0.61 \\
\hline U. States & US & 0.0198 & 242.2710 & 0.1886 & -0.2634 & -2.2834 & 0.99 & 1.40 & 1.17 \\
\hline Turkey & TK & 0.0675 & 108.5870 & -0.1392 & 0.1887 & 0.1628 & 0.95 & 4.62 & 3.36 \\
\hline Canada & CA & 0.0229 & 16.2986 & -0.0599 & 0.2466 & 0.4197 & 0.91 & 2.60 & 1.80 \\
\hline Australia & AU & 0.0069 & -132.7130 & 0.4593 & -2.4803 & 4.0450 & 0.98 & 0.88 & 0.73 \\
\hline India & IN & 0.0170 & 570.4850 & 0.4125 & -1.3173 & -5.5529 & 0.98 & 2.22 & 1.76 \\
\hline South Korea & $\mathrm{KO}$ & 0.0194 & 1.7850 & -0.4727 & 0.0862 & 2.1007 & 0.71 & 3.47 & 2.88 \\
\hline South Africa & SA & 0.0086 & -111.6960 & -0.1304 & 1.9165 & 0.3483 & 0.88 & 2.92 & 2.26 \\
\hline Mexico & MX & 0.0085 & -388.9800 & -0.2657 & -0.1006 & 7.6060 & 0.96 & 2.46 & 1.96 \\
\hline Norway & NW & 0.0029 & 6.3745 & 25.9176 & 27.9845 & 5.5979 & 0.92 & 7.08 & 4.37 \\
\hline Argentina & AR & 0.0887 & 26.6242 & 0.0929 & -0.2592 & 0.0043 & 0.65 & 4.08 & 3.11 \\
\hline Brazil & $\mathrm{BR}$ & 0.0052 & -79.2487 & -1.8117 & 4.3649 & 3.5434 & 0.73 & 1.32 & 1.03 \\
\hline Romania & $\mathrm{RO}$ & 0.0473 & -110.2140 & -0.2857 & 1.6859 & 0.4990 & 0.78 & 3.85 & 3.08 \\
\hline Russia & RU & 0.0026 & 4.5728 & -0.2241 & 2.4194 & 5.6264 & 0.82 & 2.33 & 1.87 \\
\hline China & $\mathrm{CN}$ & 0.0761 & -32.301 & 0.007195 & -0.1904 & 0.4675 & 0.93 & 1.02 & 0.98 \\
\hline Egypt & EG & 0.0048 & 3650.58 & 3.9466 & -5.5601 & -45.438 & 0.85 & 9.34 & 7.26 \\
\hline Malaysia & MY & 0.0084 & -14.2784 & 1.22723 & -0.34465 & -2.8331 & 0.96 & 2.72 & 1.60 \\
\hline Netherlands & NL & 0.0514 & -18.3229 & -0.009616 & 0.03517 & 0.1293 & 0.89 & 0.53 & 0.44 \\
\hline Denmark & DK & 0.1214 & -267.396 & 0.2248 & -3.1632 & 8.3738 & 0.82 & 18.46 & 11.05 \\
\hline Venezuela & VE & 0.0395 & 430.71 & 0.7332 & -2.9439 & -1.8455 & 0.98 & 4.45 & 2.84 \\
\hline Luxembourg & LU & 0.0030 & 1.9222 & 7.6382 & 15.577 & 5.9798 & 0.95 & 10.88 & 6.18 \\
\hline Chile & CL & 0.0050 & -173.676 & 1.49187 & -21.7849 & 28.408 & 0.90 & 2.96 & 2.16 \\
\hline Bulgaria & BG & 0.3458 & -70.4437 & -0.2307 & 1.0372 & 0.6317 & 0.81 & 8.74 & 6.91 \\
\hline Hungary & $\mathrm{HU}$ & 0.0043 & -1.6880 & 0.47095 & -2.9961 & 3.1167 & 0.20 & 4.86 & 3.73 \\
\hline Austria & AT & 0.0123 & 103.726 & -0.3691 & 1.1992 & 1.1188 & 0.80 & 0.69 & 0.55 \\
\hline Iran & IR & 0.4274 & 6.6421 & -0.1759 & 0.9101 & -1.4569 & 0.74 & 14.85 & 11.69 \\
\hline
\end{tabular}

Figure A1 of Appendix A gives all the adjustments obtained for the 36 countries analysed. Those adjustments show a broad range of behaviours in evolution of the EAF technology in those countries. This evolution goes from monotone increasing (Belgium, Turkey, India, United States) to others in which after reaching a maximum penetration there is a clear decline (Japan, Sweden). For South Korea there is a recognisable decrease in the penetration of EAF in the period studied, that is later recovered. What is common in almost all panels of Figure A1 is the capacity of the Expression (3) to model the worldwide diffusion of the EAF technology. According to the determination coefficient, $R^{2}$, the adjustment hardly worked for Hungary. This can be explained by the fact that in this country there are just only two blast furnaces (BF) and two EAF (see Table 3). Therefore, in this case, operational particularities of those few facilities can introduce a noise that the model is not able to grasp. In other countries that also have a small number of facilities (such as Portugal, Finland, Norway, Netherlands, Denmark and Luxembourg) this is not observed. 
Table 3 provides the installed capacities in 2015 from the traditional route (BF-BOF) and the recycling route (EAF), as well as the number of blast furnaces and electrical arc furnaces [32]. This table allows us to see that some countries have a small number of facilities and low production. In those countries small variations in individual facilities can alter significantly, and in a few years, the production share of the EAF technology. We can see in Figure A1 that newcomers in steel production adopt clean process more quickly than incumbents [33], since the latter are more limited by the age of the structure and the need to expand existing capacity processes.

Table 3. Installed capacities and number of blast furnaces (BF) and AC and DC EAF in 2015 in the countries under study.

\begin{tabular}{|c|c|c|c|c|c|}
\hline \multirow{2}{*}{ Country } & & \multicolumn{2}{|c|}{ Capacity (Mt) } & \multirow{2}{*}{ Number of BF } & \multirow{2}{*}{ Number of EAF } \\
\hline & & BF & EAF & & \\
\hline Belgium & $\mathrm{BE}$ & 4.43 & 4.52 & 2 & 7 \\
\hline Germany & $\mathrm{DE}$ & 33.67 & 16.21 & 18 & 39 \\
\hline Spain & ES & 4.48 & 17.37 & 2 & 27 \\
\hline France & FR & 12.81 & 7.57 & 8 & 20 \\
\hline Italy & IT & 14.51 & 24.18 & 8 & 38 \\
\hline Poland & PL & 7.34 & 4.6 & 4 & 10 \\
\hline Portugal & PT & 0 & 1.8 & 0 & 2 \\
\hline Finland & FI & 2.48 & 1.3 & 2 & 2 \\
\hline Sweden & SE & 4.13 & 2.41 & 3 & 8 \\
\hline United Kingdom & UK & 12.78 & 4.75 & 7 & 8 \\
\hline Japan & $\mathrm{JP}$ & 93.64 & 31.37 & 28 & 69 \\
\hline United States & US & 38.33 & 74.82 & 24 & 128 \\
\hline Turkey & TK & 10.78 & 33.1 & 11 & 31 \\
\hline Canada & $\mathrm{CA}$ & 8.48 & 7.69 & 6 & 17 \\
\hline Australia & $\mathrm{AU}$ & 3.8 & 1.52 & 2 & 3 \\
\hline India & IN & 79.6 & 33.12 & 84 & 71 \\
\hline South Korea & $\mathrm{KO}$ & 45.82 & 27.73 & 13 & 37 \\
\hline South Africa & SA & 4.93 & 5.7 & 3 & 10 \\
\hline Mexico & $\mathrm{MX}$ & 5.55 & 19.86 & 4 & 28 \\
\hline Norway & NW & 0 & 0.8 & 0 & 1 \\
\hline Argentina & AR & 3.9 & 3.67 & 3 & 9 \\
\hline Brazil & $\mathrm{BR}$ & 41.38 & 11.32 & 52 & 27 \\
\hline Romania & $\mathrm{RO}$ & 4.34 & 3.71 & 3 & 10 \\
\hline Russia Federation & RU & 59.42 & 34.68 & 47 & 51 \\
\hline China & $\mathrm{CN}$ & 480.27 & 54.31 & 425 & 134 \\
\hline Egypt & EG & 1.44 & 11.79 & 4 & 22 \\
\hline Malaysia & MY & 1.03 & 8.53 & 2 & 14 \\
\hline Netherlands & NL & 6.3 & 0.26 & 2 & 2 \\
\hline Denmark & DK & 0 & 0 & 0 & 0 \\
\hline Venezuela & $\mathrm{VE}$ & 0 & 7.1 & 0 & 10 \\
\hline Luxembourg & LU & 0 & 3.15 & 0 & 3 \\
\hline Chile & $\mathrm{CL}$ & 1.15 & 0.41 & 2 & 2 \\
\hline Bulgaria & BG & 0 & 3.71 & 0 & 10 \\
\hline Hungary & $\mathrm{HU}$ & 1.31 & 0.95 & 2 & 2 \\
\hline Austria & $\mathrm{AT}$ & 6.35 & 1.47 & 6 & 3 \\
\hline Iran & IR & 3.7 & 18.04 & 4 & 30 \\
\hline Total (36 countries) & & 993.22 & 477.82 & 778 & 875 \\
\hline Rest of World & & 101.52 & 96.45 & 84 & 240 \\
\hline TOTAL WORLD & & 1094.74 & 574.27 & 862 & 1115 \\
\hline Coverage & & $90.7 \%$ & $83.3 \%$ & $90.2 \%$ & $78.5 \%$ \\
\hline
\end{tabular}




\subsection{Influence of the Parameter $\boldsymbol{K}$ in the Diffusion of EAF Technology}

This section shows how the historical evolution of the diffusion of EAF technology in one country is affected by different values of the ratio $L^{2} / K$. The blue curve of Figure 1 corresponds to the historical share of EAF in Japan. The green curve labelled with " $K$ " is the best adjustment obtained with the approach of Section 2.1, that is, solving Equation (5), in which Equations (3) and (4) are embedded. This curve agrees quite well with the observed values (as proved by a MAE of $0.61 \%$ ). The remaining curves show the effect of different values of $\boldsymbol{K}$ in Equation (3).

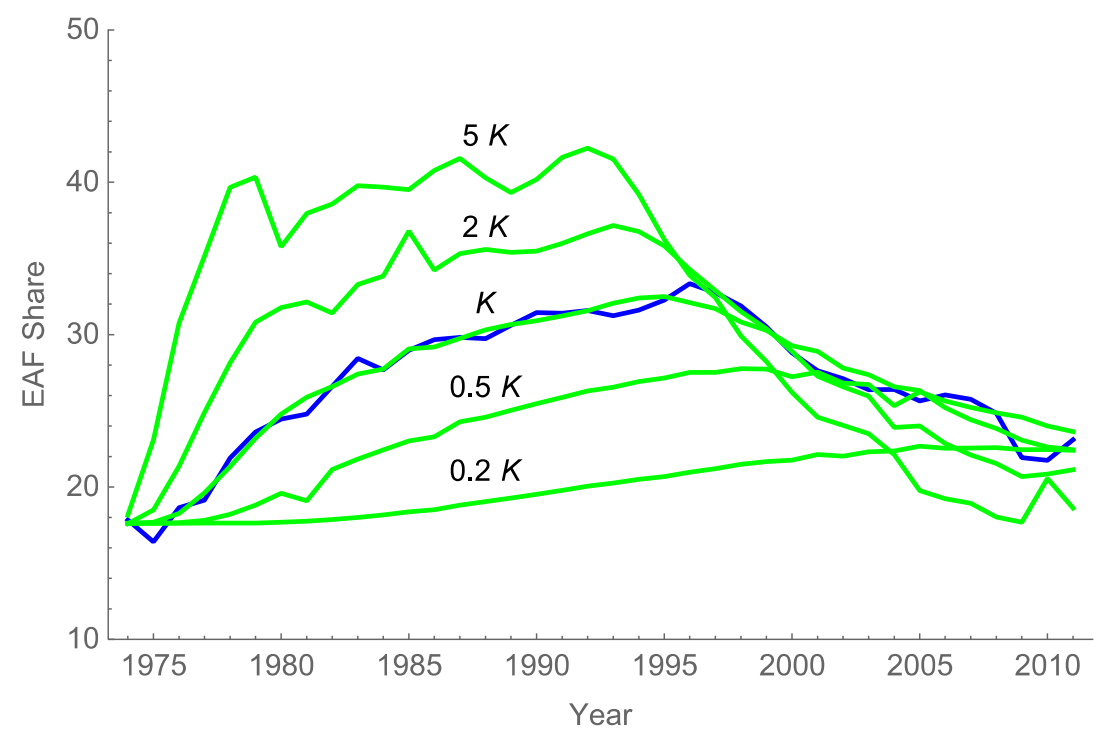

Figure 1. Influence of the parameter $K$ (that summarises the combined effect of the barriers on the take-up of innovations) over the diffusion of EAF technology in Japan.

An increase of the value of $K$, ceteris paribus, means that the solution of the model overreacts to the conditions that favour the use (or dis-use) of the new technology. Similarly, for lower values of $K$ the adjusted model is not able to achieve the penetration of EAF technology observed in Japan. It is also noticeable that higher values of $K$ provoke an earlier and higher maximum of the penetration share of EAF technology. Moreover, in this case, when the conditions are less favourable to the adoption of EAF technology, it is abandoned earlier and more intensively.

Figure 2 shows that countries with similar values of $K$ can have very different shares of EAF technology. For example, in 2011 the Netherlands, Romania, Spain and Venezuela, whose $K$ values are $0.0514,0.04473,0.0469$ and 0.0395 , had a share of EAF technology of $0 \%, 51 \%, 71 \%$ and $100 \%$, respectively. Furthermore, in the Netherlands the EAF share was decreasing whereas in the other three countries it was increasing (Venezuela reached a share of $100 \%$ in the 1990 s and has not varied since then). 


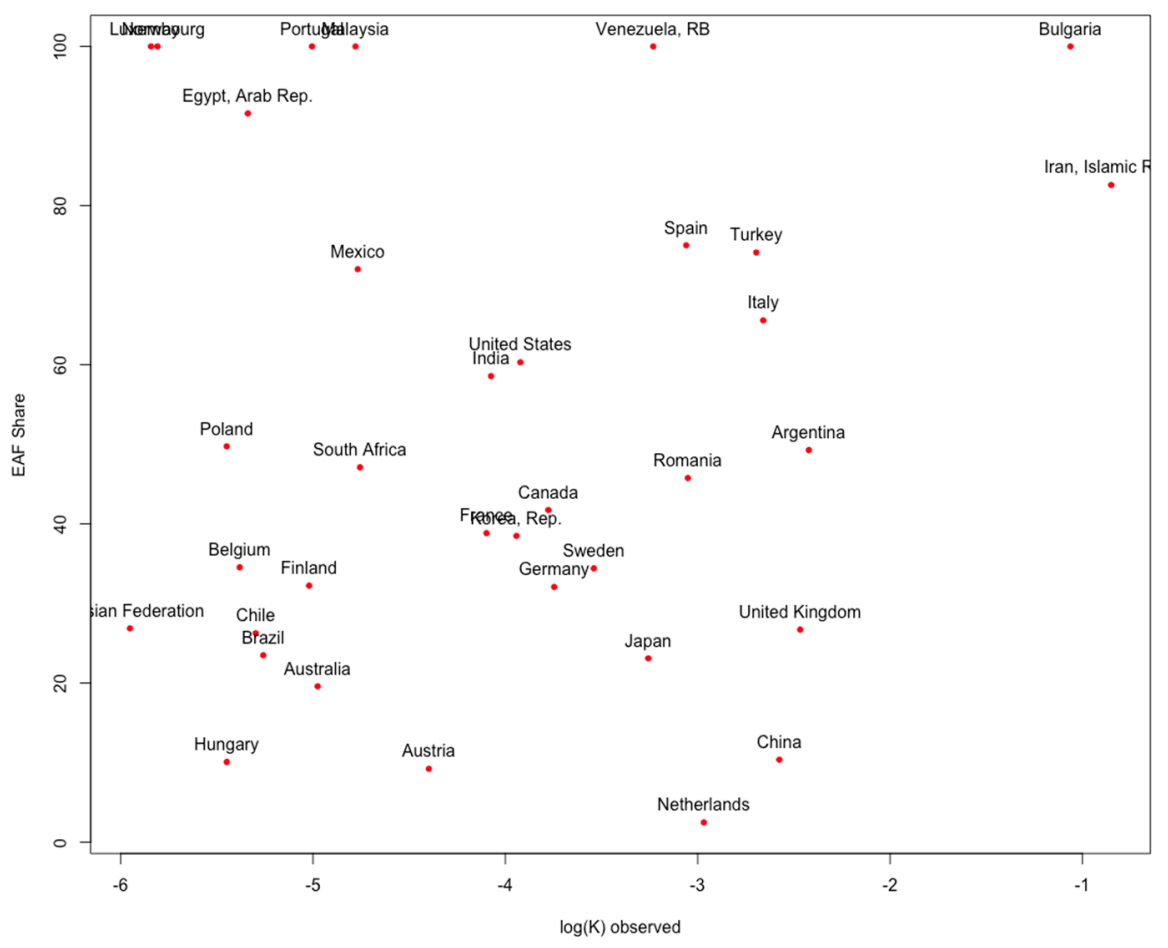

Figure 2. Observed values of the parameter $\boldsymbol{K}$ and share of the EAF technology in 2011.

In addition, countries with the same EAF share correspond with a wide spectrum of $K$ values. For example, countries with a total diffusion of the EAF technology by 2011, such as Luxembourg, Norway, Portugal, Malaysia, Venezuela and Bulgaria (named in increasing order of the parameter $\mathbf{K}$ ) have $K$ values ranging from 0.003 to 0.3458 .

As shown in Figure 1, the higher the $K$ value, the more sensitive the country is to the conditions that can alter the investment (or disinvestment) in the EAF technology. Even though the value of $K$ is related to the structure of the country and the barriers present, its interpretation is not straightforward, i.e., we cannot say that the deployment of the EAF technology in Luxembourg, Norway and Portugal faced more barriers than in in Malaysia, Venezuela and Bulgaria. The relationship between the parameter $\mathrm{K}$ and the traits (barriers) of each country will be analysed in next section.

In Figure 2, we can also observe some clustering of the values of $\boldsymbol{K}$ for some countries. For example, Germany, France, Sweden and Korea have similar penetration of EAF technology and $K$ value. With a similar $K$ value, but higher penetration of the technology, are India and the United States. Based on the previous sensitivity analysis of the value of $K$ we would say that these countries have had a similar dynamic behaviour incorporating EAF technology.

\subsection{Traits of the EAF and the Steel Industry}

Before analysing the relationship between the parameter that summarises the effect of barriers, and the potential barriers themselves, this section provides some information that comes in handy to understand the historical competitiveness of the recycling route (based on the EAF technology).

The main component of the EAF production cost is the raw material cost, i.e., scrap, that even though is a global commodity (whose historical evolution can be read in Table 1), suffers some regional variations. Moya el al. [34] provides a production cost comparison of two products from the recycling route and the traditional route (BF-BOF) for nine non-EU countries and the EU. Eight of those countries (Brazil, China, India, Japan, Russia, South Korea, Turkey and United States) are also included in this analysis. This reference presents how small differences in the scrap cost (that is around two thirds of the total cost) determine the position of each country in the cost curve. Two out of the three countries with 
the highest production costs (China and Japan) in [34] exhibit a clear decline in the historical penetration of the EAF technology. In South Korea the trend is not so clear. The opposite can also be observed for the countries with lowest production in 2013 (Russia, Brazil and India). It is worth noting that even though electricity represents around $5 \%$ of the final price in 2011 , in 2000 this percentage was up to $20 \%$.

Beside these considerations for the production costs, it is convenient to provide some notes about the different steel products and their added value. According to its final shape and use, steel can be classified into two big groups: flat products and long products. The flat products, produced mainly by the integrated route, provide the highest added value of steel, whereas the long products, produced mainly in the recycling route are in the lower range of added value. In any case, the historically clear difference between the production route and long or flat products is waning out, improving the competitiveness of the EAF technology. Nowadays $100 \%$ of long products and $70 \%-80 \%$ of flat products can be made with scrap [35].

\section{Overall Effect of Barriers}

In Section 2.2 we applied the approach suggested in Moya [8] to model the diffusion of the electrical arc furnace in 36 countries. This approach produces a good description of the diffusion of the EAF technology from 1974 to 2010 in those countries. The only necessary ingredients are the parameters that can be considered as main drivers of the innovation, and the overall effect of the barriers. The reason for considering the prices of electricity, scrap and steel as main drivers is that the right combination of values of these parameters can determine whether a new investment is worthwhile. Following the approach of Moya [8], other factors affecting the cost-effectiveness of the investment should be considered as an additional component of the driver of innovations, leaving the coefficient $K$ to account for the effects that affect the observed diffusion of the technology and cannot be included in a cost-effectiveness assessment. As mentioned, one of the advantages of this approach is that it provides in a single parameter the hampering effect of all barriers. Sorrel et al. [12] define barriers as "a postulated mechanism that inhibits investments in technologies that are both energy efficient and (apparently) economically efficient". We assume that all potential factors affecting the cost-effectiveness of the investment are included when determining what is "economically efficient". That is, in our definition of the main driver for innovation, function " $\mathrm{f}$ " of Expression (3), we include all factors that are an intrinsic part of a cost-effectiveness analysis (such as, among other factors, policies directly modifying the costs). Whereas the parameter $K$ is reserved for barriers (sociological, regulatory or of any other kind) or supportive measures that can affect the timing of a strategic decision, e.g., the lack of confidence of decision makers in the prices incorporated in the cost-effectiveness analysis, mimicry among investors, etc. In fact, the effect of all barriers or support measures, and therefore of the coefficient $\boldsymbol{K}$ in the diffusion model, see Figure 1, is to delay or speed-up the adoption of innovations.

Although, the literature describing barriers and their effect is quite broad, there are some basic references $[11,12]$ with recent updates $[9,13]$ that contain some classifications extensively used in the literature on barriers $[36,37]$. Sorrel's classification makes the distinction between barriers due to market failure (that should receive the attention of policy-makers), and non-market failure barriers (out of the scope of active policies). Market failure occurs when the requirements for efficient allocation of resources are violated (market prices known by all participants in the market, zero transaction costs...). Much of the early criticism to the first attempts to categorise barriers $[38,39]$ comes from the failure to make this distinction in the identified barriers. Furthermore, in the refinements to the taxonomy of barriers provided by Cagno et al. [13], they also add a crucial structural perspective, categorising the barriers as internal and external to the enterprise.

To represent potential barriers, and their evolution for the countries during the period of interest, we use some of the world development indicators [40]. Among all the indicators, we preselect those (Table A1) that could be worth retaining as pertaining to one of the categories of barriers indicated in $[9,13]$.

The rest of this paper is devoted to establishing whether the parameter $K$ can be related, using linear relationship, with some of the preselected indicators. Note that although the number of indicators 
of Table A1 might seem high, Kemp and Volpi [33] quantify the number of relevant factors affecting the adoption decision of individual companies, and thus the technology diffusion, as well over a hundred.

\section{Estimation of the Influence of Barriers in the Observed Values of the $\boldsymbol{K}$}

For each country (36) we have 81 time series (between 1974 and 2011), one per preselected indicator. We use the mean of the values of each time series and its slope as independent variables or explicative parameters. This section will analyse whether a linear model with some of those explicative parameters is able to account for the observed values of $K$.

The starting point of any linear regression model is to assure that the conditions required by any linear model are met. Therefore, we try to assure that the potential indicators, predictors or explanatory variables are transformed in such a way that there are not any outliers and there is heteroscedasticity in the input parameters. Since many of our parameters are proportions (bounded between 0 and 1 ) we try a slight variation of the logit transformation. The slight variation is included to keep in the sample zeros and ones. For this same latter reason, we also try two additional modifications of the logarithmic transformation. The exact expression of these transformations can be read in the code of the supplementary material; we refer to these transformations as logit, llogg and llog2. We also introduce as potential explanatory variables the inverse of the previous values. In order to be able to apply the inverse transformation, we replace the zeros by the lowest value of the parameter. Since some of the variables do not require any transformation, and have units orders of magnitude higher than the rest of explanatory variables, we normalise all of them.

Finally, we disregard all explanatory variables with empty values for one or more countries and those for which no transformation is able to eliminate the outliers. A serious drawback of the needed transformations is a loss of interpretability of the individual values [41]. All the steps followed can be read and reproduced in the ' $R$ ' script of the supplementary material.

As a second step, and in order to discard multicollinearity problems, we disregard predictors with pairwise absolute correlations higher than a certain threshold, 0.75 . We follow the algorithm suggested in [42] to accomplish this step. Moreover, when analysing the models we also check the variance inflation factor [43].

The challenge of having more potential predictors than observations is commonly handled by the latest developments in statistical learning methods. One of the main challenges when constructing models when there are more predictors than observations, is to avoid overfitting the model. An overfitted model has a high variance error (different sets of observations produce large errors in the estimation) although it also has a minimised bias (the difference between the observed and the predicted values is minimised). This paper uses the cross-validation error (estimated using the function "cv.glm" [44], see the supplementary material) to find the right balance between both kind of errors.

In short, the cross-validation sets aside part of the population of values (called train data) to construct a model, and checks the variance error with the values set aside (called test data). We use 6 folds in the k-fold validation. We also prove all possible models with two predictors and interactions and tree predictors, cross-interactions and powers of second order.

The third model of Table 4 is the best one identified. Following the notation of the statistical software R, the ":" indicates an interaction among regressors. Table 5 details the meaning of regressors from B1 to B4. The second column of this latter table indicates the transformation applied to work with the corresponding data. The third column of Table 5 indicates whether the regressor corresponds to the average values or to the linear slopes of the time series between 1974 and 2011. Since we are working with standardised values, the numerical values of the estimated regressors in Table 4 serve as a sensitivity measure of the relevance of the predictors. 
Table 4. Best models for $K$ obtained with the indicators of Table A1.

\begin{tabular}{ccccc}
\hline \# of Model & Model & Adj $\boldsymbol{R}^{\mathbf{2}}$ & vif & Cv_err \\
\hline 1 & $-0.2374+0.7888 \mathrm{~B} 1: \mathrm{B} 2$ & 0.35 & & 0.68 \\
2 & $-0.8195+0.7212 \mathrm{B3}^{2}+0.5813 \mathrm{~B}^{2}+0.8943 \mathrm{~B} 3: \mathrm{B} 4$ & 0.43 & 5.65 & 0.61 \\
3 & $-0.8843+0.5918 \mathrm{~B}^{2}+0.4924 \mathrm{~B}^{2}+0.7197 \mathrm{~B} 3: \mathrm{B} 4+0.6312 \mathrm{~B} 1: \mathrm{B} 2$ & 0.67 & 5.80 & 0.40 \\
\hline
\end{tabular}

The first model of Table 4 is the best one of first degree obtained considering all possible combinations of two indicators, including the interactions between them. The second model of Table 4 is the best model of second degree that can be obtained among all possible combinations of two indicators, including their cross-interactions.

Table 5. Description of the regressors incorporated into the models of Table 4.

\begin{tabular}{cccccc}
\hline Predictor & Transf. & $\begin{array}{c}\text { Parameter of } \\
\text { the Time Series }\end{array}$ & Series Code & Indicator Name & Unit \\
\hline B1 & llogg & mean & NY.GDP.DEFL.KD.ZG & Inflation, GDP deflator & (annual \%) \\
\hline B2 & llog2 & slope & IP.PAT.NRES & $\begin{array}{c}\text { Patent applications, } \\
\text { non-residents }\end{array}$ & Number of \\
\hline B3 & none & slope & FD.AST.PRVT.GD.ZS & $\begin{array}{c}\text { Domestic credit to } \\
\text { private sector by banks }\end{array}$ & $(\%$ of GDP) \\
\hline B4 & inverse & mean & GC.TAX.TOTL.GD.ZS & Tax revenue & (\% of GDP) \\
\hline
\end{tabular}

Since there is no relationship between model 1 and 2 of Table 4 (the regression of the predictors of model 1 against model 2 has an adjusted $R^{2}=-0.04$ ) we can get the third model of Table 4 combining both of them. This latter model (the third) is by far the best model of all of them. It manages to account for two thirds of the variability of the output (parameter $K$ ). Moreover, it has a lower cross-validation error, which guarantees that this more populated model (with more explanatory variables) is not overfitted (the fact that the cross-validation error is lower than the in the two previous models means that the third model achieves the best trade-off between the bias and the variance errors).

Although the predictors identified in the third model are not any surprise, one has to be wary of the large number of models tried. The exhaustive quest carried out can mean that the significant relationship found is more one of chance rather than causality. We could try to extract conclusions about the rationality of the model analysing how the different combination of predictors contribute to the lower or higher values of $\boldsymbol{K}$. For that, first we recall from Section 2.2, that the higher the values of $K$, the more prone the country is to react to favourable or dis-favourable conditions. That is, the quicker the penetration or phasing out of the technology.

The upper panel of Figure 3 shows the estimated value of the $K$ predicted by the third model of Table 4 versus the observed $\boldsymbol{K}$ values. Recall that the observed $\boldsymbol{K}$ values, in Table 2, were obtained minimising the Expresion (5). The lower panel of Figure 3 breaks down the contribution of the interaction of B1 and B2 (B1:B2, last term of model 3) drawn in in blue, and the contribition of the other terms of model 3 (the same terms that form model 2) drawn in red. The interaction B1:B2 (the only term of model 1) is the interaction of the slope of the historical evolution of the number of patents by non residents and the inflation (GDP deflator). The transformation and normalisation applyed to the trend of the number of patents by non residents together with the interaction with the inflation makes the intepretation of this term in the model difficult. For example, for the highest $K$ observed (Iran) the contribution of this term is one of the smallest, whereas for the second highest $K$ observed (Bulgaria) the contributions of the interaction of B1:B2 and the rest of the model are reversed. In general terms, for the higher and the lower values of $K$, the contribution of the intearction B1:B2 has the same sign as the rest of the model, and for some intermediary values of $\boldsymbol{K}$ both contributions (more or less) cancel each other. 

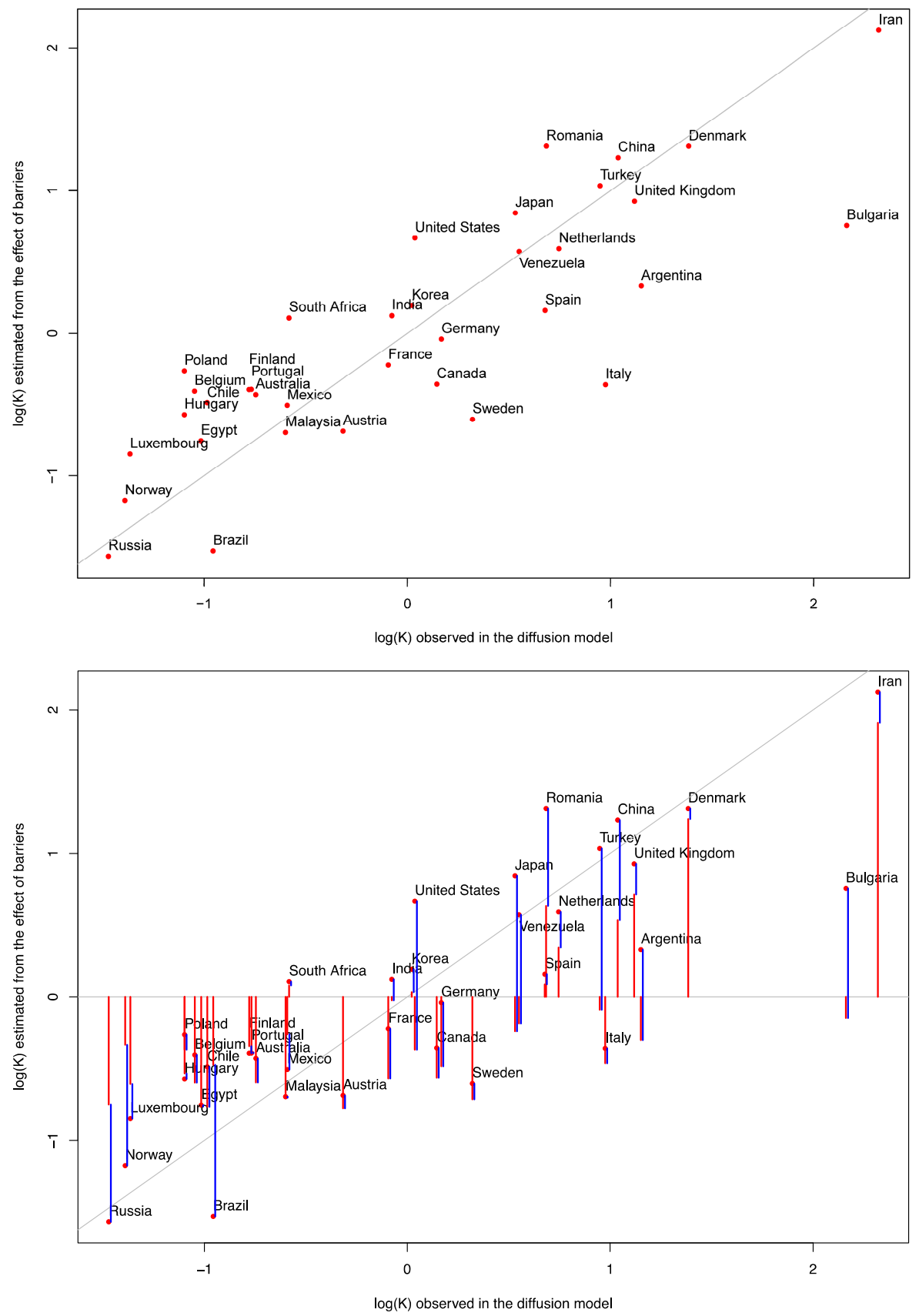

Figure 3. Upper panel: observed vs estimated values of parameter $K$ that summarises the effect of the barriers. Lower panel: contribution of the terms of model 1 and 2 to the $K$ estimated by model 3 .

When we replace the regressor B2 (slope of the time series of the Number of Patent applications by non-residents) by the slope of the number of patent applications by residents, the model is still able to account for half of the variability of the observed variable $\left(R^{2}\right.$ of 0.48 and has a cross-validation error of 0.6). The same holds when we replace regressor B1 (average value of the Inflation, GDP deflator) by the slope of the same time series (with an $R^{2}$ of 0.48 and a cross-validation error of 0.59 ). This drives us to re-affirm that the values of $K$ estimated are more fruit of causality than of randomness.

\section{Discussion}

In the ensuing discussion, we consider it convenient to recap how the research has been carried out and its main findings. This paper presents in Section 2 an extensive use of the approach by Moya [8] to 
model the diffusion of a clean technology. However, its main originality lies in the analysis conducted in Section 3 to relate a parameter that (in the new diffusion model) accounts for the combined effect of barriers to potential barriers in the countries analysed. The novelty of this latter analysis is not due to the use of some of the latest statistical tools developed in the context of statistical learning methods, but to the possibility to relate an objective measure of the relevance of barriers, the $K$ parameter observed in the diffusion model, with potential barriers existing in the countries under study. In this manner we are able to tell which of those potential barriers have been more influential in the diffusion process without any additional intervention. Note that so far, the only source of information about the relevance of any barriers were the surveys to decision makers about what prevents investments in new technologies.

The results of Section 2 prove that the new approach to model the diffusion of a clean technology is able to reproduce satisfactory the worldwide diffusion of the EAF technology. The list of 36 countries analysed assure a good global coverage. This approach only requires adjustment of 5 parameters in each country, and uses the same evolution of prices of steel, scrap and electricity for all countries as a main driver of the adoption of innovations. Following this new approach, the only parameter not related to the drivers of innovation accounts for the traits of the society that in each country favours or hampers the take-up of innovations.

Section 3 of this paper explores whether or not we are able to find a relationship among the observed parameter $K$ and some other parameters that can serve as a proxy of the barriers to the diffusion of innovations. Recall that the observed value of parameter $K$ of the diffusion model measures the traits of the society that influence the diffusion of the innovation. In this task, although we are able to produce some interesting results, we faced some challenges. The first of them is that the dependent variable (parameter $K$ ) is the result of an optimisation problem (Equation (5)), i.e., although it allows some good adjustments between the diffusion of the technology and the observed values, it is not exempt from uncertainties. The second, and more daunting challenge, is that the number of countries (observations of parameter $K$ or dependent variable) is much lower than the number of parameters that could serve as a proxy for some barriers, a problem worsened if we also include the inverses of those parameters and all potential interactions. Furthermore, we also have to deal with the fact that our collection of countries produces many atypical and leverage observations in some of the explanatory or independent variables. The outliers are not always in the same countries. The presence of outliers can be mitigated by applying transformations, and when the transformation proves useless, by disregarding the independent variable of the analysis. In order to avoid problems related to multicollinearity, we also disregarded independent variables highly related to others. Thanks to recent advances in statistical methods $[41,45]$ (developed in the scope of machine learning and data mining) there are ways (using the cross-validation error) to overcome the risk of overfitting the model when there are more potential explanatory variables than observations.

All in all, the model that best reproduces the observed values of the parameter $K$ includes explanatory variables that are usually associated with barriers; such as the number of patents [15,46], inflation [9], financing capacity $[9,47]$ and taxes [15]. Indeed, the model containing a combination of these variables is able to account for two thirds of the variability observed in the parameter $K$.

We refrain from extracting more conclusions from the results of Section 3, mainly acknowledging that the results may be impaired by the burdensome statistical steps involved. However, a comprehensive understanding of how the barriers to innovation affect the spread of those innovations can offer huge rewards to policy-makers. This reward could come from the design of measures to overcome the most relevant identified barriers, from indicators paying attention to the evolution of those barriers and from the analysis of the effect of existing policies.

\section{Conclusions}

This new approach to model the global historical diffusion of a clean energy technology produces a good fit between its estimations and the historical diffusion observed. This new approach is composed 
only by terms that accounts for the driver of innovations and an additional parameter that collects the overall effect of the barriers to the take up of innovations in each country. The combination of both kind of parameters (drivers and barriers) within a model able to describe quite closely the diffusion of innovations is the main trait and advantage of this approach. According to its theoretical basis, this paper also confirms the existence of a linear relationship between the overall parameter that summarises the combined effect of all barriers in the diffusion model and some specific barriers (the number of patents per capita, inflation, financing capacity and taxes). The variability and nature of the parameters that measure the barriers in the countries analysed require the application of some statistical techniques in order to be able to use linear regression models. This comes at the expense of the loss of interpretability of the results. However, this paper shows how a linear model with only four barriers is able to account for two thirds of the variability of the parameter that summarises their combined effect in the diffusion model. The identified barriers are in line with some of those usually described in the literature. The approach followed in this paper opens up new possibilities for identifing and quantifing the preventive role of barriers in the diffusion of innovations, and therefore, has the potential to support policy makers in the design of policies aimed to promote the spread of innovations.

Supplementary Materials: All the code and input information necessary to reproduce the findings of this paper are accessible on line from: https://gitlab.jrc.nl/e3p-repository/global-diffusion-eaf. File S1: README.MD, File S2: World_EAF.nb, File S3: barriers2innovation.R, File S4: World_EAF.txt, File S5: percent_newCountries.txt, File S6:convolution.txt, File S7: barriers2innovation.R, File S8: WDI2.csv, File S9: transformaciones.csv, File S10: Summary_Minimizations.csv, File S11: plots_and_hist2.pdf.

Conflicts of Interest: The author declares no conflict of interest.

\section{Abbreviations}

The following abbreviations are used in this manuscript:

$\begin{array}{ll}\text { BF-BOF } & \text { Blast Furnace-Basic Oxygen Furnace } \\ \text { EAF } & \text { Electric arc furnace } \\ \text { RMSE } & \text { Root-mean-square error } \\ \text { MAE } & \text { Mean absolute error } \\ \text { VIF } & \text { Variance inflation factor } \\ \text { GDP } & \text { Gross domestic product }\end{array}$

\section{Appendix A}

In this appendix we provide in Table A1 the indicators from [40] used as potential predictors of the parameters $K$ that collects the overall effect of the barriers. A more detailed description of the indicators that form part of the models of Table 4 is provided in Table A2.

Table A1. Indicators from [40] that can serve as potential predictors of the parameters $K$ that collects the overall effect of the barriers.

\begin{tabular}{|c|c|c|}
\hline & Indicator Code & Indicator Name \\
\hline 1 & FS.AST.DOMS.GD.ZS & Domestic credit provided by financial sector (\% of GDP) \\
\hline 2 & FD.AST.PRVT.GD.ZS & Domestic credit to private sector by banks (\% of GDP) \\
\hline 3 & SL.IND.EMPL.ZS & Employment in industry (\% of total employment) \\
\hline 4 & IC.REG.COST.PC.ZS & Cost of business start-up procedures (\% of GNI per capita) \\
\hline 5 & EG.IMP.CONS.ZS & Energy imports, net ( $\%$ of energy use) \\
\hline 6 & BX.KLT.DINV.WD.GD.ZS & Foreign direct investment, net inflows ( $\%$ of GDP) \\
\hline 7 & EG.USE.COMM.FO.ZS & Fossil fuel energy consumption (\% of total) \\
\hline 8 & NY.GDP.MKTP.KD.ZG & GDP growth (annual \%) \\
\hline 9 & NV.IND.TOTL.KD.ZG & Industry, value added (annual \% growth) \\
\hline 10 & NY.GDP.DEFL.KD.ZG & Inflation, GDP deflator (annual \%) \\
\hline 11 & CM.MKT.LCAP.GD.ZS & Market capitalisation of listed companies (\% of GDP) \\
\hline 12 & CM.MKT.TRAD.GD.ZS & Stocks traded, total value (\% of GDP) \\
\hline 13 & GC.TAX.TOTL.GD.ZS & Tax revenue ( $\%$ of GDP) \\
\hline 14 & GC.TAX.GSRV.RV.ZS & Taxes on goods and services ( $\%$ of revenue) \\
\hline 15 & GC.TAX.YPKG.RV.ZS & Taxes on income, profits and capital gains (\% of revenue) \\
\hline
\end{tabular}


Table A1. Cont.

\begin{tabular}{|c|c|c|}
\hline & Indicator Code & Indicator Name \\
\hline 16 & GC.TAX.YPKG.ZS & Taxes on income, profits and capital gains (\% of total taxes) \\
\hline 17 & IC.TAX.TOTL.CP.ZS & Total tax rate (\% of commercial profits) \\
\hline 18 & NE.TRD.GNFS.ZS & Trade ( $\%$ of GDP) \\
\hline 19 & SL.UEM.TOTL.ZS & Unemployment, total (\% of total labour force) (modeled ILO estimate) \\
\hline 20 & SP.RUR.TOTL.ZS & Rural population (\% of total population) \\
\hline 21 & IC.ELC.TIME & Time required to get electricity (days) \\
\hline 22 & IC.REG.DURS & Time required to start a business (days) \\
\hline 23 & IC.EXP.DURS & Time to export (days) \\
\hline 24 & IC.TAX.DURS & Time to prepare and pay taxes (hours) \\
\hline 25 & IC.LGL.PROC & Procedures to enforce a contract (number) \\
\hline 26 & IC.IMP.DOCS & Documents to import (number) \\
\hline 27 & IP.JRN.ARTC.SC & Scientific and technical journal articles \\
\hline 28 & EG.USE.PCAP.KG.OE & Energy use (kg of oil equivalent per capita) \\
\hline 29 & EG.USE.ELEC.KH.PC & Electric power consumption (kWh per capita) \\
\hline 30 & NY.GDP.PCAP.KD & GDP per capita (constant 2005 US\$) \\
\hline 31 & IC.EXP.COST.CD & Cost to export (US\$ per container) \\
\hline 32 & IC.IMP.COST.CD & Cost to import (US\$ per container) \\
\hline 33 & BX.KLT.DINV.CD.WD & Foreign direct investment, net inflows (BoP, current US\$) \\
\hline 34 & IP.PAT.NRES & Patent applications, nonresidents \\
\hline 35 & IP.PAT.RESD & Patent applications, residents \\
\hline 36 & NV.MNF.MTRN.ZS.UN & Machinery and transport equipment (\% of value added in manufacturing) \\
\hline 37 & NV.IND.MANF.ZS & Manufacturing, value added (\% of GDP) \\
\hline 38 & EN.POP.DNST & Population density (people per sq. km of land area) \\
\hline 39 & SP.POP.GROW & Population growth (annual \%) \\
\hline 40 & CSPC & kg Crude Steel per Capita \\
\hline 41 & CS.GDP & Crude Steel production (KG)/GDP (US constant 2005) \\
\hline 42 & EG.ELC.ACCS.ZS & Access to electricity (\% of population) \\
\hline 43 & FB.BNK.CAPA.ZS & Bank capital to assets ratio $(\%)$ \\
\hline 44 & IC.FRM.CMPU.ZS & Firms competing against unregistered firms ( $\%$ of firms) \\
\hline 45 & IC.TAX.GIFT.ZS & Firms expected to give gifts in meetings with tax officials (\% of firms) \\
\hline 46 & IC.FRM.FREG.ZS & Firms formally registered when operations started (\% of firms) \\
\hline 47 & IC.FRM.TRNG.ZS & Firms offering formal training ( $\%$ of firms) \\
\hline 48 & IC.FRM.INFM.ZS & Firms that do not report all sales for tax purposes (\% of firms) \\
\hline 49 & IC.FRM.BNKS.ZS & Firms using banks to finance investment ( $\%$ of firms) \\
\hline 50 & BM.KLT.DINV.GD.ZS & Foreign direct investment, net outflows (\% of GDP) \\
\hline 51 & NE.GDI.FPRV.ZS & Gross fixed capital formation, private sector (\% of GDP) \\
\hline 52 & FP.CPI.TOTL.ZG & Inflation, consumer prices (annual \%) \\
\hline 53 & SL.TLF.TERT.ZS & Labor force with tertiary education (\% of total) \\
\hline 54 & IC.TAX.LABR.CP.ZS & Labor tax and contributions (\% of commercial profits) \\
\hline 55 & FR.INR.LEND & Lending interest rate $(\%)$ \\
\hline 56 & SL.UEM.LTRM.ZS & Long-term unemployment (\% of total unemployment) \\
\hline 57 & IC.TAX.PRFT.CP.ZS & Profit tax ( $\%$ of commercial profits) \\
\hline 58 & FR.INR.RINR & Real interest rate $(\%)$ \\
\hline 59 & GC.TAX.GSRV.VA.ZS & Taxes on goods and services ( $\%$ value added of industry and services) \\
\hline 60 & GC.TAX.INTT.RV.ZS & Taxes on international trade ( $\%$ of revenue) \\
\hline 61 & SL.EMP.WORK.ZS & Wage and salaried workers, total (\% of total employed) \\
\hline 62 & IC.GOV.DURS.ZS & $\begin{array}{l}\text { Time spent dealing with the requirements of government regulations (\% of senior } \\
\text { management time) }\end{array}$ \\
\hline 63 & NY.GDP.DEFL.ZS & GDP deflator (base year varies by country) \\
\hline 64 & IC.ELC.DURS & Delay in obtaining an electrical connection (days) \\
\hline 65 & IC.CUS.DURS.EX & Average time to clear exports through customs (days) \\
\hline 66 & IC.LGL.DURS & Time required to enforce a contract (days) \\
\hline 67 & IC.FRM.DURS & Time required to obtain an operating license (days) \\
\hline 68 & IC.IMP.DURS & Time to import (days) \\
\hline 69 & IC.ELC.OUTG & Power outages in firms in a typical month (number) \\
\hline 70 & IC.EXP.DOCS & Documents to export (number) \\
\hline 71 & EG.USE.COMM.GD.PP.KD & Energy use (kg of oil equivalent) per \$1000 GDP (constant 2011 PPP) \\
\hline 73 & FP.CPI.TOTL & Consumer price index $(2010=100)$ \\
\hline 74 & EG.ELC.PROD.KH & Electricity production $(\mathrm{kWh})$ \\
\hline 75 & EG.EGY.PROD.KT.OE & Energy production (kt of oil equivalent) \\
\hline 76 & EG.GDP.PUSE.KO.PP.KD & GDP per unit of energy use (constant 2011 PPP \$ per kg of oil equivalent) \\
\hline 77 & NY.GDP.MKTP.KD & GDP (constant 2005 US\$) \\
\hline 78 & NV.IND.TOTL.KD & Industry, value added (constant 2005 US\$) \\
\hline 79 & SP.POP.TOTL & Population, total \\
\hline 80 & SP.POP.TECH.RD.P6 & Technicians in R\&D (per million people) \\
\hline 81 & NV.IND.MANF.KD & Manufacturing, value added (constant 2005 US\$) \\
\hline
\end{tabular}


Table A2. Longer description of the terms that for part of the models of Table 4.

\begin{tabular}{cl}
\hline \multicolumn{1}{c}{ Series Code } & \multicolumn{1}{c}{ Long Description } \\
\hline NY.GDP.DEFL.KD.ZG & $\begin{array}{l}\text { Inflation as measured by the annual growth rate of the GDP implicit deflator shows the } \\
\text { rate of price change in the economy as a whole. The GDP implicit deflator is the ratio } \\
\text { of GDP in current local currency to GDP in constant local currency. }\end{array}$ \\
\hline IP.PAT.NRES & $\begin{array}{l}\text { Patent applications are worldwide patent applications filed through the Patent } \\
\text { Cooperation Treaty procedure or with a national patent office for exclusive rights for } \\
\text { an invention—a product or process that provides a new way of doing something or } \\
\text { offers a new technical solution to a problem. A patent provides protection for the } \\
\text { invention to the owner of the patent for a limited period, generally 20 years. }\end{array}$ \\
\hline FD.AST.PRVT.GD.ZS & $\begin{array}{l}\text { Domestic credit to private sector by banks refers to financial resources provided to the } \\
\text { private sector by other depository corporations (deposit taking corporations except } \\
\text { central banks), such as through loans, purchases of nonequity securities, and trade } \\
\text { credits and other accounts receivable, that establish a claim for repayment. For some } \\
\text { countries these claims include credit to public enterprises. }\end{array}$ \\
\hline GC.TAX.TOTL.GD.ZS & $\begin{array}{l}\text { Tax revenue refers to compulsory transfers to the central government for public } \\
\text { purposes. Certain compulsory transfers such as fines, penalties, and most social } \\
\text { security contributions are excluded. Refunds and corrections of erroneously collected } \\
\text { tax revenue are treated as negative revenue. }\end{array}$ \\
\hline
\end{tabular}

As mentioned in the main text, the blue curves of Figure A1 are the historical evolution of the penetration share of the EAF technology $\left(E A F_{\text {observed }}\right)$ in each of the 36 countries analysed. The green curves of Figure A1, the $E A F_{\text {estimated }}$, are the best fit of obtained for $E A F_{\text {observed }}$.
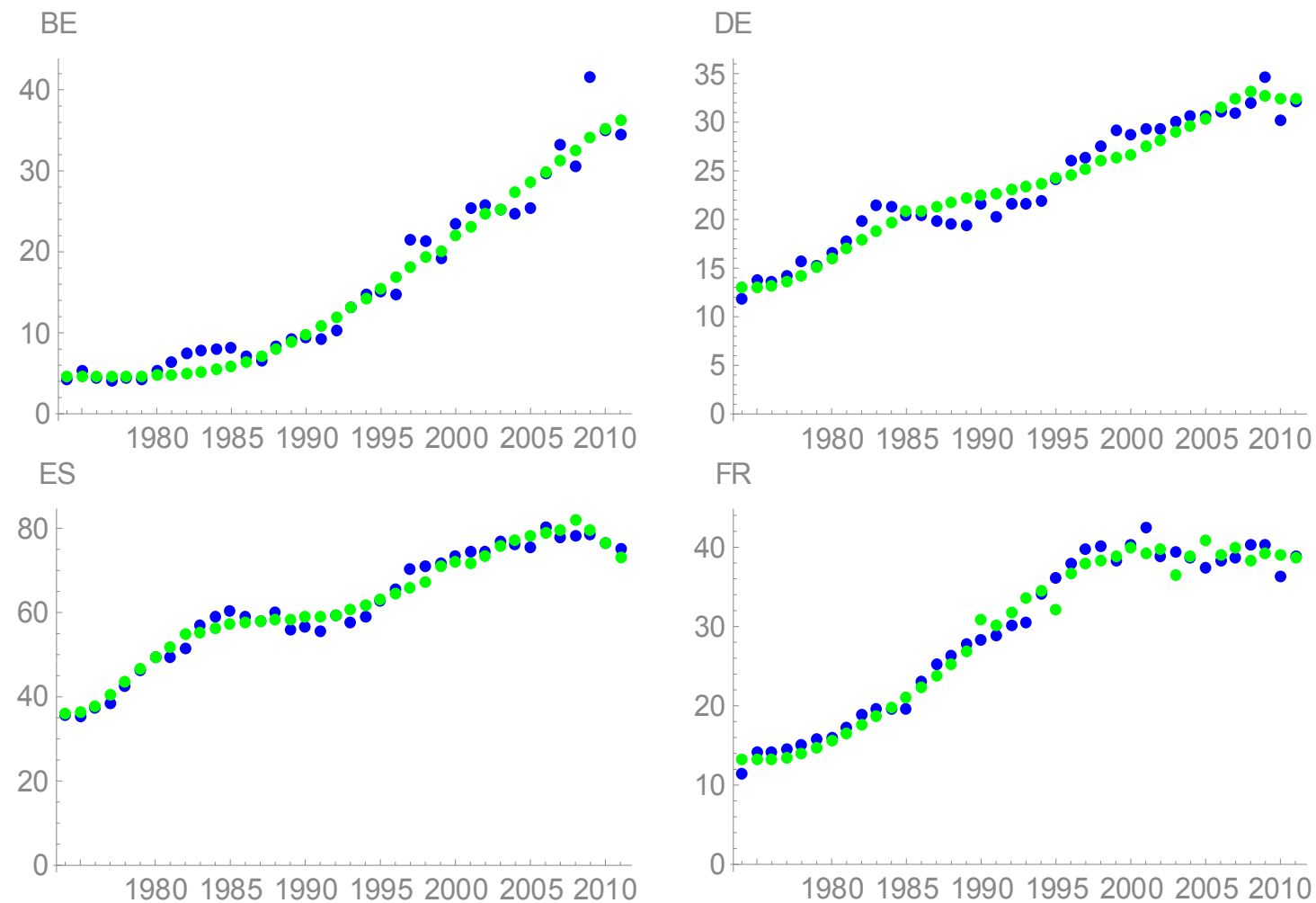

Figure A1. Cont. 

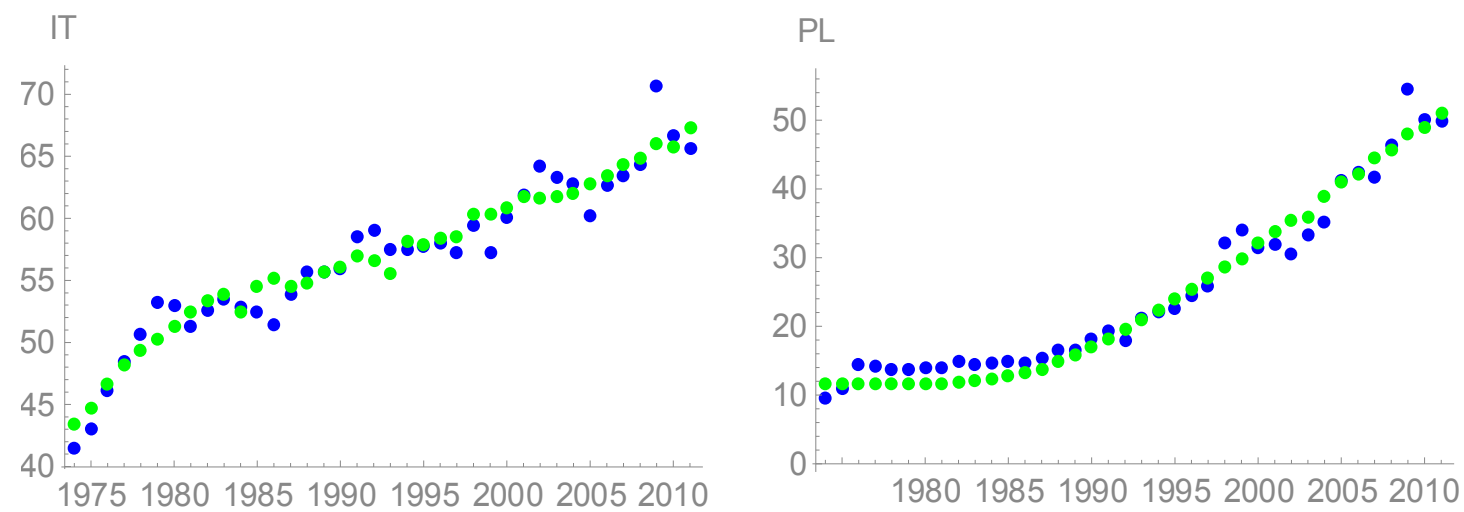
PT
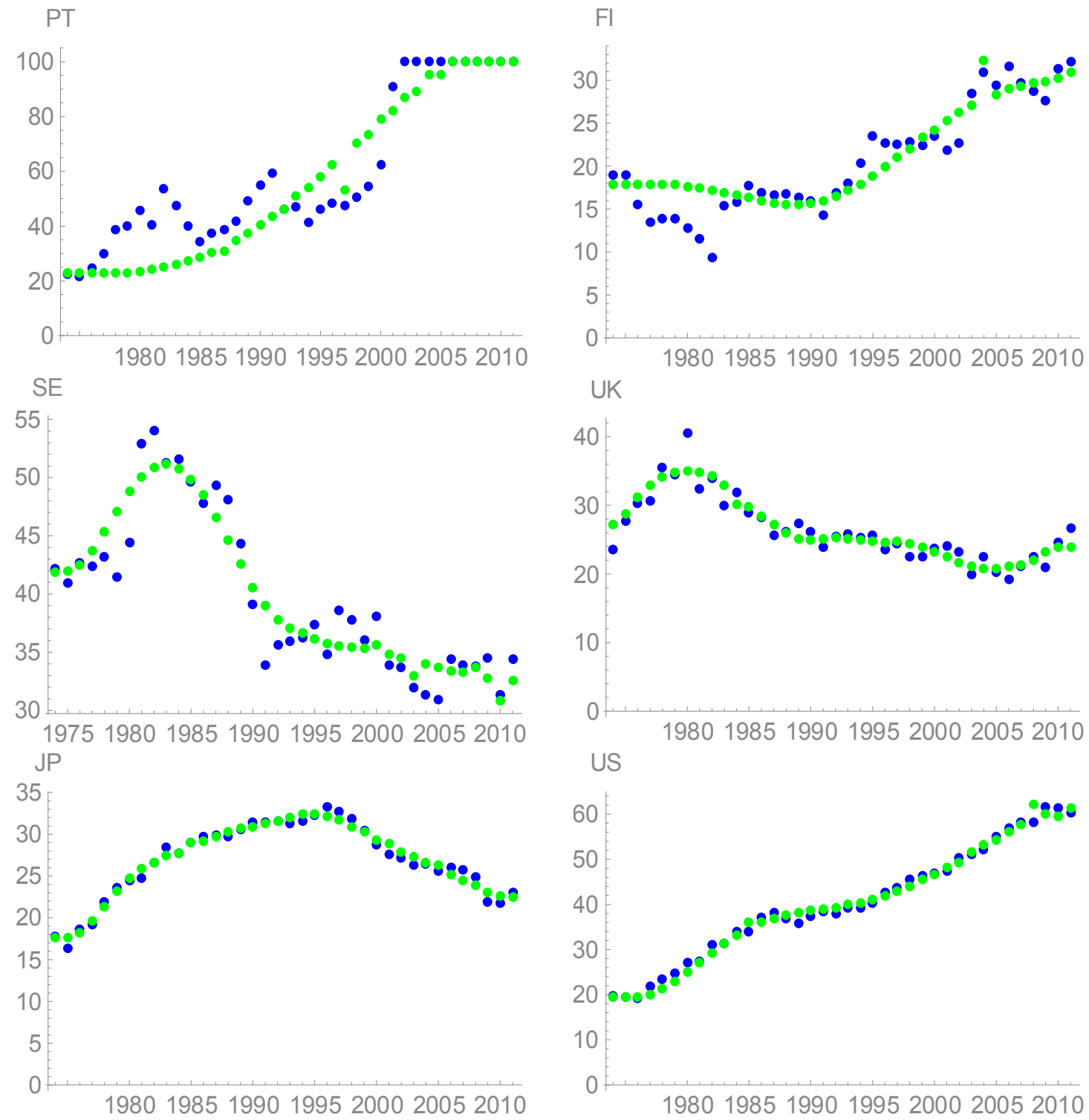

Figure A1. Cont. 

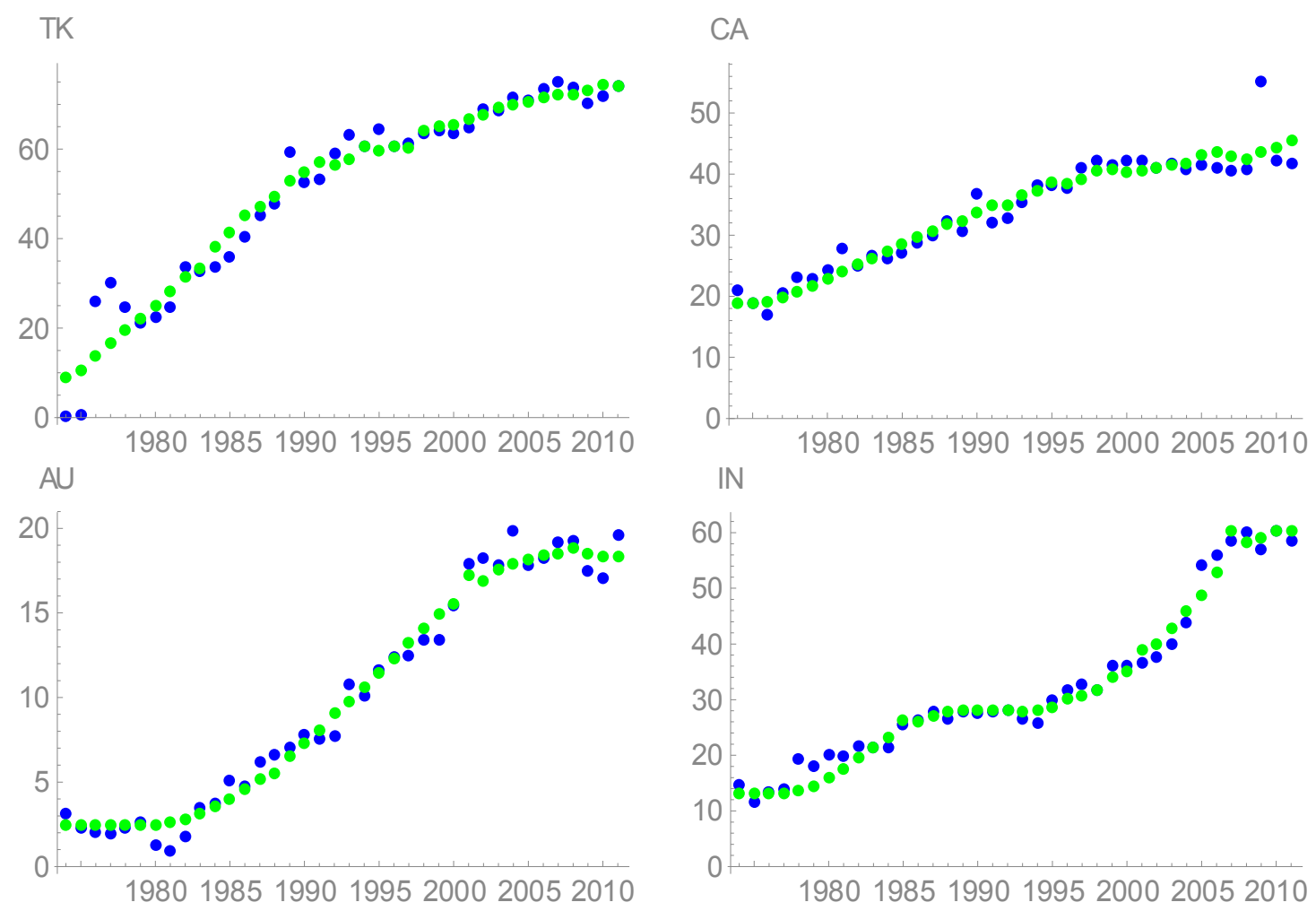
IN
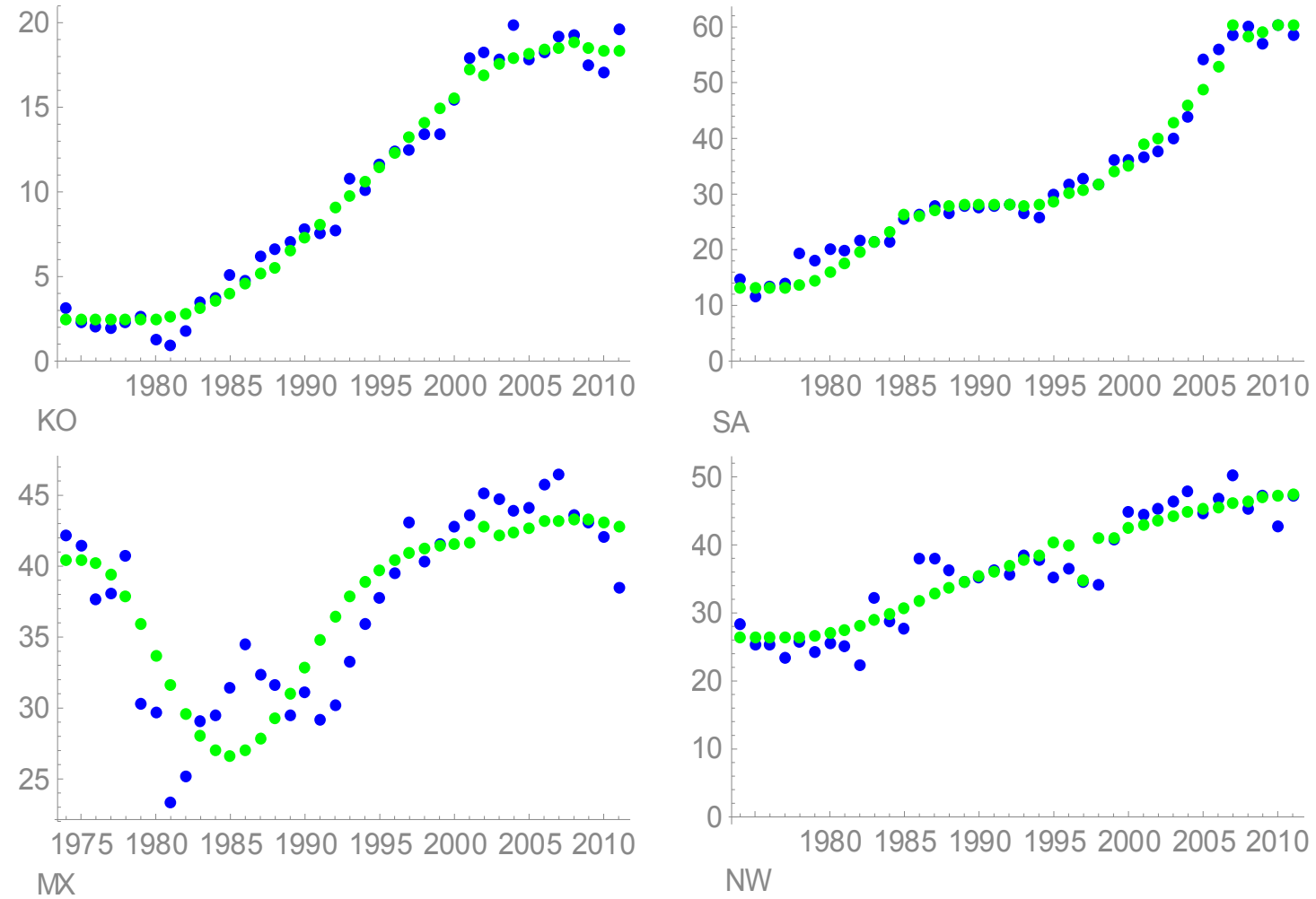
SA
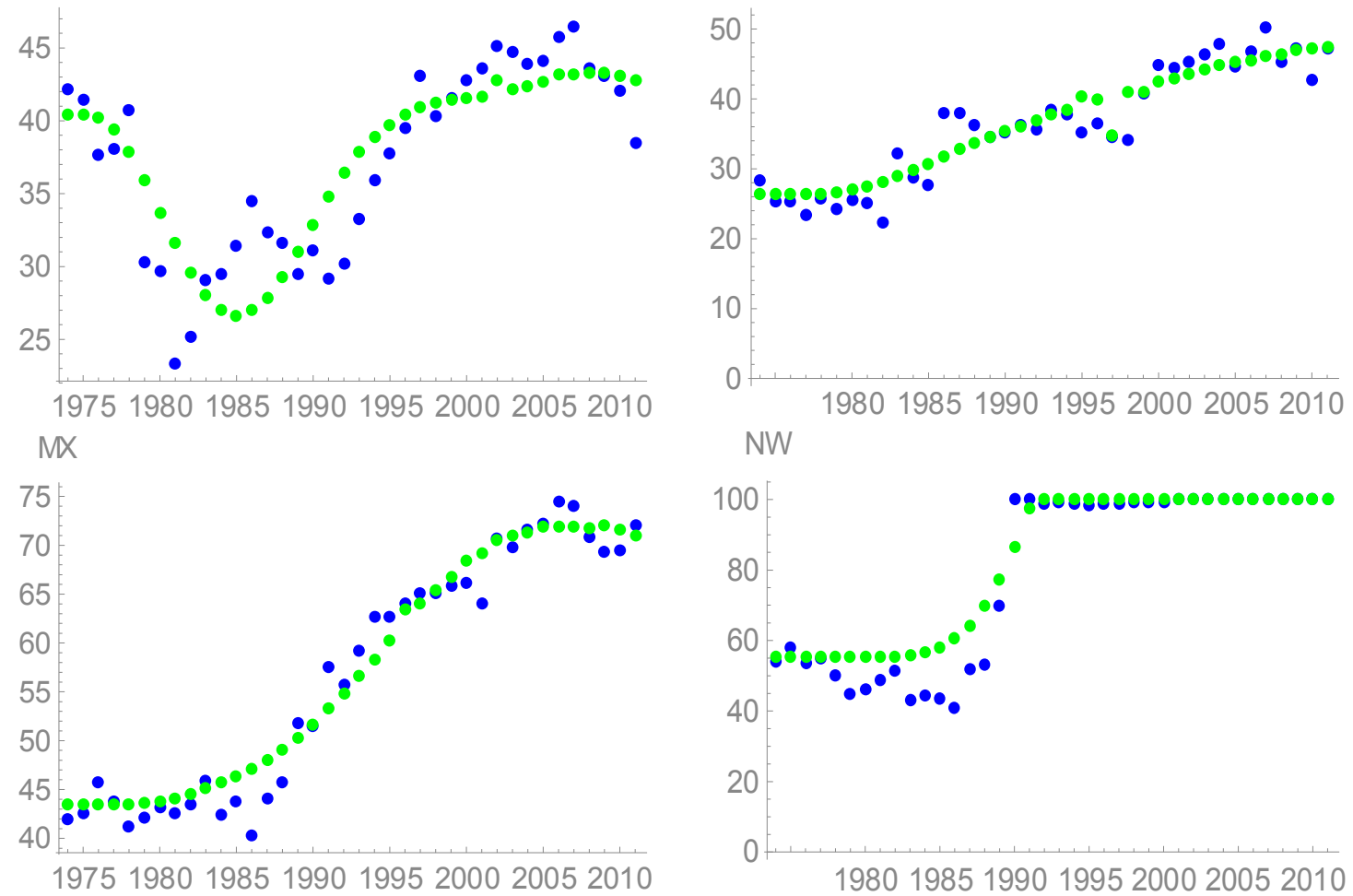

Figure A1. Cont. 

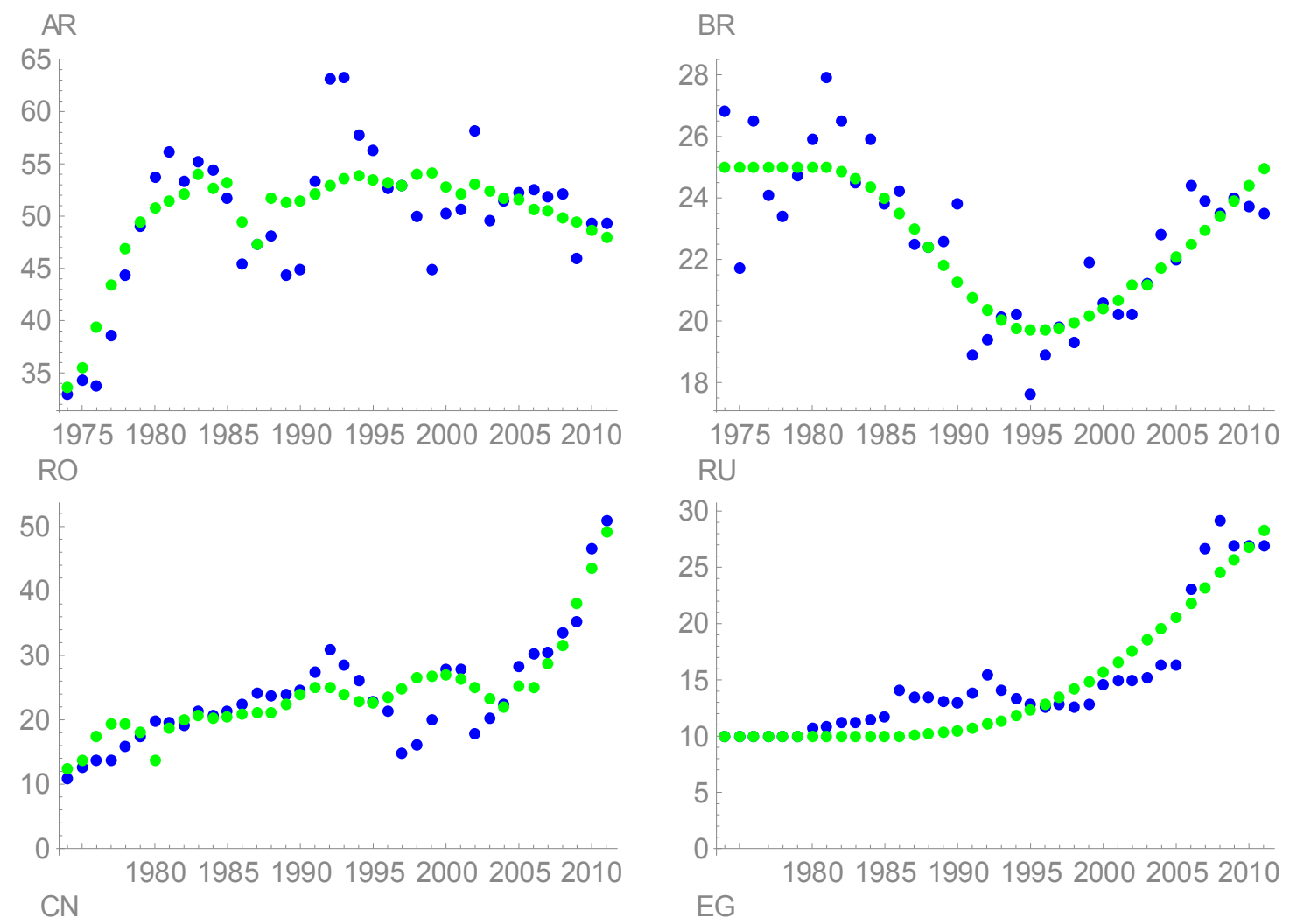
$\mathrm{RU}$
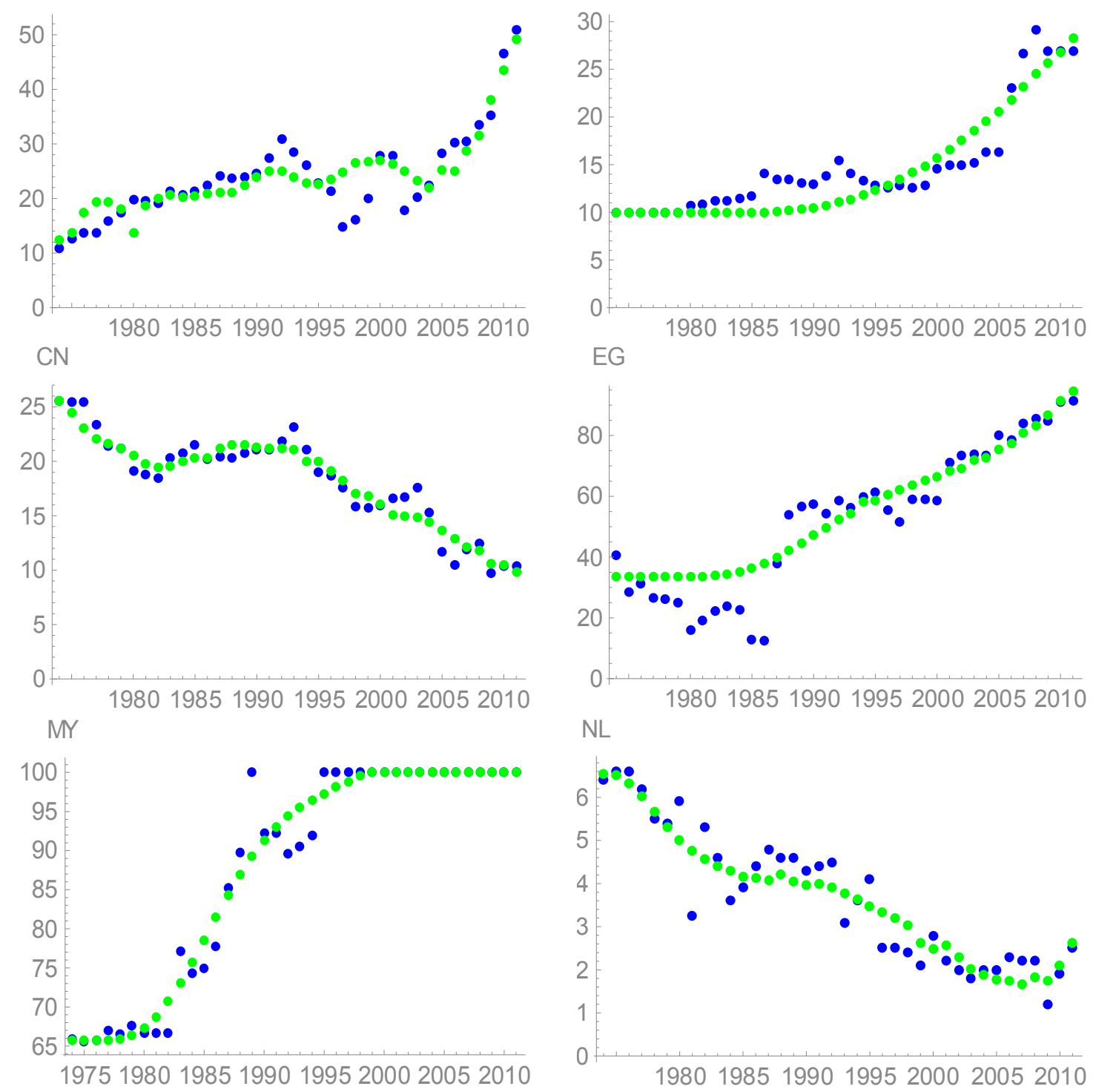

Figure A1. Cont. 

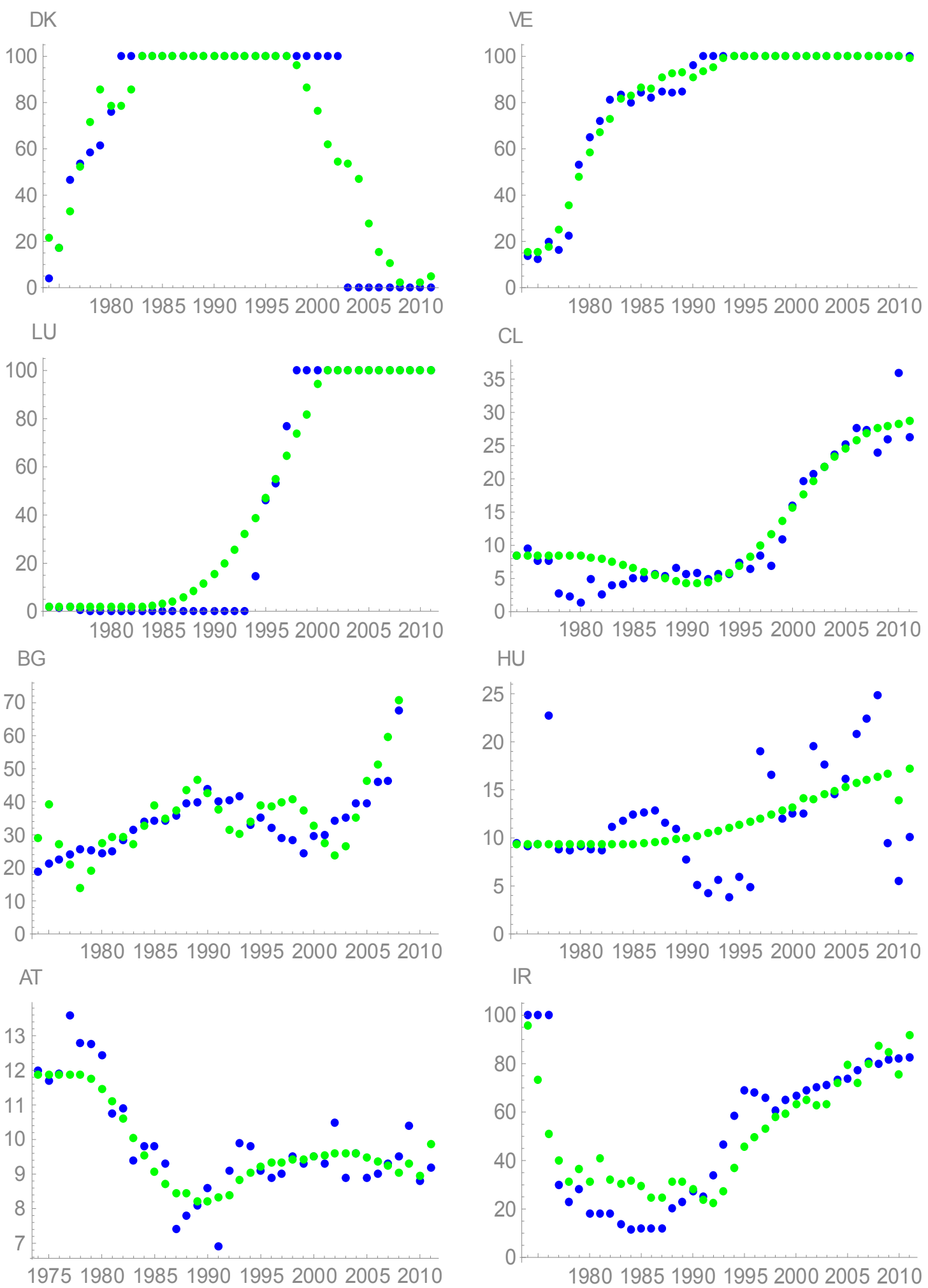
IR

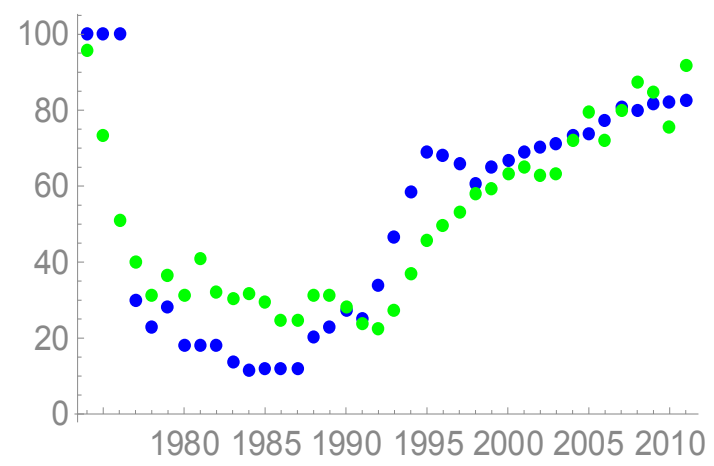

Figure A1. Adjustments provided by the model (in green) to the percentages of steel from the EAF route in the 36 countries under study (in blue).

\section{References}

1. Fleiter, T.; Plötz, P. Encyclopedia of Energy, Natural Resource, and Environmental Economics; Elsevier: Amsterdam, The Netherlands, 2013. 
2. Jaffe, A.B.; Stavins, R.N. The energy-efficiency gap What does it mean? Energy Policy 1994, 22, 804-810. [CrossRef]

3. Hirst, E.; Brown, M. Closing the efficiency gap: Barriers to the efficient use of energy. Resour. Conserv. Recycl. 1990, 3, 267-281. [CrossRef]

4. Geroski, P.A. Models of technology diffusion. Res. Policy 2000, 29, 603-625. [CrossRef]

5. Meade, N.; Islam, T. Modelling and forecasting the diffusion of innovation-A 25-year review. Int. J. Forecast. 2006, 22, 519-545. [CrossRef]

6. Chandrasekaran, D.; Tellis, G.J. A Critical Review of Marketing Reseach on Diffusion of New Products; Emerald Group Publishing Limited: Bradford, UK, 2007; pp. 39-80.

7. Jaffe, A.B.; Stavins, R.N. The energy paradox and the diffusion of conservation technology. Resour. Energy Econ. 1994, 16, 91-122. [CrossRef]

8. Moya, J.A. A Natural Analogy to the Diffusion of Energy-Efficient Technologies. Energies 2016, 9, 471. [CrossRef]

9. Sorrell, S.; Mallett, A.; Nye, S. Barriers to Industrial Energy Efficiency: A Literature Review; Elsevier: Vienna, Austria, 2011.

10. Blumstein, C.; Krieg, B.; Schipper, L.; York, C. Overcoming social and institutional barriers to energy conservation. Energy 1980, 5, 355-371. [CrossRef]

11. Sorrell, S.; O'Malley, E.; Schleich, J.; Scott, S. The Economics of Energy Efficiency: Barriers to Cost-Effective Investment; Edward Elgar Publishing: Cheltenham, UK, 2004.

12. Sorrell, S.; Schleich, J.; Scott, S.; O’Malley, E. Reducing Barriers to Energy Efficiency in Public and Private Organizations; Science and Technology Policy Unit of the University of Sussex: Brighton, UK, 2000.

13. Cagno, E.; Worrell, E.; Trianni, A.; Pugliese, G.; FISHER, J.C.; Cagno, E.; Worrell, E.; Trianni, A.; Pugliese, G. A novel approach for barriers to industrial energy efficiency. Renew. Sustain. Energy Rev. 2013, 19, 290-308. [CrossRef]

14. Sardianou, E. Barriers to industrial energy efficiency investments in Greece. J. Clean. Prod. 2008, 16, 1416-1423. [CrossRef]

15. Suriñach, J.; Autant-Bernard, C.; Manca, F.; Massard, N.; Moreno, R. The Diffusion/Adoption of Innovation in the Internal Market; European Commision. DG for Economic and Financial Affairs: Brussels, Belgium, 2009.

16. De Groot, H.L.F.; Verhoef, E.T.; Nijkamp, P. Energy Saving By Firms: Decision-Making, Barriers and Policies. Energy Econ. 2001, 23, 717-740. [CrossRef]

17. Chen, Y.-T.; Chang, D.-S.; Chen, C.-Y.; Chen, C.-C. The policy impact on clean technology diffusion. Clean Technol. Environ. Policy 2012, 14, 699-708. [CrossRef]

18. Thiam, D.R. Policy instruments for a market penetration of low carbon technology in developing nations. Int. J. Energy Sect. Manag. 2012, 6, 465-487. [CrossRef]

19. Mallett, A.; Nye, S.; Sorrell, S. Policy Options to Overcome Barriers to Industrial Energy Efficiency in Developing Countries; United Nations Industrial Development Organization: Vienna, Austria, 2011.

20. Fleiter, T.; Worrell, E.; Eichhammer, W. Barriers to energy efficiency in industrial bottom-up energy demand models-A review. Renew. Sustain. Energy Rev. 2011, 15, 3099-3111. [CrossRef]

21. Algehed, J.; Wirsenius, S.; Jönsson, J. Modelling energy efficiency and carbon dioxide emissions in energy-intensive industry under stringent $\mathrm{CO}_{2}$ policies: Comparison of top-down and bottom-up approaches and evaluation of usefulness to policy makers. In Proceedings of the eceee 2009 Sumer Study, Act! Innovate! Deliver! Reducing Energy Demand Sustainably, La Colle sur Loup, France, 1-6 June 2009.

22. Worrell, E.; Ramesohl, S.; Boyd, G. Advances in energy forecasting models based on engineering economics. Annu. Rev. Environ. Resour. 2004, 29, 345-381. [CrossRef]

23. Crank, J. The Mathematics of Diffusion, 2nd ed.; Clarendon Press: Oxford, UK, 1975.

24. Nill, J. Diffusion as time-dependent result of technological evolution, competition, and policies: The case of cleaner iron and steel technologies. J. Clean. Prod. 2008, 16, 58-66. [CrossRef]

25. Crompton, P. The diffusion of new steelmaking technology. Resour. Policy 2001, 27, 87-95. [CrossRef]

26. Labson, B.S.; Gooday, P. Factors influencing the diffusion of electric arc furnace steelmaking technology. Appl. Econ. 1994, 26, 917-925. [CrossRef]

27. Reppelin-Hill, V. Trade and environment: An empirical analysis of the technology effect in the steel industry. J. Environ. Econ. Manag. 1999, 38, 283-301. [CrossRef] 
28. International Energy Agency (IEA). Electricity Information (Several Volumes). 2013. Available online: http://www.oecd-ilibrary.org/energy/electricity-information-2001_electricity-2001-en (accessed on 12 October 2013).

29. U.S. Geological Survey (USGS). Iron and Steel Scrap. Statistics and Information. 2012. Available online: http://minerals.usgs.gov/minerals/pubs/commodity/iron_\&_steel_scrap/ (accessed on October 2013).

30. The Word Bank. Global Economic Monitor (GEM) Commodities Database. Available online: http:/ / databank.worldbank.org/data/reports.aspx?source=global-economic-monitor-(gem) -commodities (accessed on 8 November 2014).

31. National Accounts Main Aggregates Database. Available online: http://unstats.un.org/unsd/snaama/ dnlList.asp (accessed on 31 March 2014).

32. Worldsteel. Steel Statistical Yearbook (Several Volumes). 2013. Available online: http:/ /www.worldsteel.org/ (accessed on 25 september 2013).

33. Kemp, R.; Volpi, M. The diffusion of clean technologies: A review with suggestions for future diffusion analysis. J. Clean. Prod. 2008, 16, S14-S21. [CrossRef]

34. Moya, J.A.; Boulamanti, A. Production Costs from Energy-Intensive Industries in the EU and Third Countries; Publications Office of the European Union: Luxembourg, 2016.

35. Laplace Conseil. Impacts of Energy Market Developments on the Steel Industry. In Proceedings of the 74th Session of the OECD Steel Committee, Paris, France, 1-2 July 2013.

36. Gan, L. Globalization of the automobile industry in China: Dynamics and barriers in greening of the road transportation. Energy Policy 2003, 31, 537-551. [CrossRef]

37. Rohdin, P.; Thollander, P. Barriers to and driving forces for energy efficiency in the non-energy intensive manufacturing industry in Sweden. Energy 2006, 31, 1500-1508. [CrossRef]

38. Sutherland, R.J. Market Barriers to Energy-Efficiency Investments. Energy J. 1991, 12, 15-34. [CrossRef]

39. Sutherland, R.J. The economics of energy conservation policy. Energy Policy 1996, 24, 361-370. [CrossRef]

40. The Word Bank. World Development Indicators 2014. Available online: http://databank.worldbank.org/ data/reports.aspx?source=world-development-indicators (accessed on 4 November 2014).

41. Kuhn, M.; Johnson, K. Applied Predictive Modeling; Springer: New York, NY, USA, 2013.

42. Kuhn, M. Building Predictive Models in R using the Caret Package. J. Stat. Softw. 2008, 28, 1-26. [CrossRef]

43. Fox, J.; Weisberg, S. An R Companion to Applied Regression; SAGE Publications, Inc.: Thousand Oaks, CA, USA, 2011.

44. Canty, A.; Ripley, B. Boot: Bootstrap R (S-Plus) Functions. Available online: https://cran.r-project.org/web/ packages/boot/citation.html (accessed on 4 November 2014).

45. James, G.; Witten, D.; Hastie, T.; Tibshirani, R. An Introduction to Statistical Learning; Springer: New York, NY, USA, 2013; Volume 103.

46. Schneider, P.H. International trade, economic growth and intellectual property rights: A panel data study of developed and developing countries. J. Dev. Econ. 2005, 78, 529-547. [CrossRef]

47. Stoneman, P. Technological Diffusion and the Financial Environment. Available online: http:/ / citeseerx.ist.psu.edu/viewdoc/download;jsessionid=22FFB63683011D2F7055DAC43FAF5E1B? doi=10.1.1.10.453\&rep=rep1\&type=pdf (accessed on 26 October 2016).

(C) 2017 by the author; licensee MDPI, Basel, Switzerland. This article is an open access article distributed under the terms and conditions of the Creative Commons Attribution (CC-BY) license (http://creativecommons.org/licenses/by/4.0/). 